\title{
Global distribution of mean age of stratospheric air from MIPAS $\mathrm{SF}_{6}$ measurements
}

\author{
G. P. Stiller ${ }^{1}$, T. von Clarmann ${ }^{1}$, M. Höpfner ${ }^{1}$, N. Glatthor ${ }^{1}$, U. Grabowski ${ }^{1}$, S. Kellmann ${ }^{1}$, A. Kleinert ${ }^{1}$, A. Linden ${ }^{1}$, \\ M. Milz ${ }^{1, *}$, T. Reddmann ${ }^{1}$, T. Steck ${ }^{1}$, H. Fischer ${ }^{1}$, B. Funke ${ }^{2}$, M. López-Puertas ${ }^{2}$, and A. Engel ${ }^{3}$ \\ ${ }^{1}$ Forschungszentrum Karlsruhe and University of Karlsruhe, Inst. für Meteorologie und Klimaforschung, Karlsruhe, Germany \\ ${ }^{2}$ Instituto de Astrofísica de Andalucía CSIC, Granada, Spain \\ ${ }^{3}$ Institut für Atmosphäre und Umwelt, J.W. Goethe Universität Frankfurt am Main, Frankfurt, Germany \\ * now at: Institutionen för Rymdvetenskap, Luleå Tekniska Universitet, Kiruna, Sweden
}

Received: 27 July 2007 - Published in Atmos. Chem. Phys. Discuss.: 18 September 2007

Revised: 3 January 2008 - Accepted: 8 January 2008 - Published: 12 February 2008

\begin{abstract}
Global distributions of profiles of sulphur hexafluoride $\left(\mathrm{SF}_{6}\right)$ have been retrieved from limb emission spectra recorded by the Michelson Interferometer for Passive Atmospheric Sounding (MIPAS) on Envisat covering the period September 2002 to March 2004. Individual $\mathrm{SF}_{6}$ profiles have a precision of $0.5 \mathrm{pptv}$ below $25 \mathrm{~km}$ altitude and a vertical resolution of $4-6 \mathrm{~km}$ up to $35 \mathrm{~km}$ altitude. These data have been validated versus in situ observations obtained during balloon flights of a cryogenic whole-air sampler. For the tropical troposphere a trend of $0.230 \pm 0.008 \mathrm{pptv} / \mathrm{yr}$ has been derived from the MIPAS data, which is in excellent agreement with the trend from ground-based flask and in situ measurements from the National Oceanic and Atmospheric Administration Earth System Research Laboratory, Global Monitoring Division. For the data set currently available, based on at least three days of data per month, monthly $5^{\circ}$ latitude mean values have a $1 \sigma$ standard error of $1 \%$. From the global $\mathrm{SF}_{6}$ distributions, global daily and monthly distributions of the apparent mean age of air are inferred by application of the tropical tropospheric trend derived from MIPAS data. The inferred mean ages are provided for the full globe up to $90^{\circ} \mathrm{N} / \mathrm{S}$, and have a $1 \sigma$ standard error of $0.25 \mathrm{yr}$. They range between 0 (near the tropical tropopause) and 7 years (except for situations of mesospheric intrusions) and agree well with earlier observations. The seasonal variation of the mean age of stratospheric air indicates episodes of severe intrusion of mesospheric air during each Northern and Southern polar winter observed, long-lasting remnants of old, subsided polar winter air over the spring and summer poles, and a rather short period of mixing with midlatitude air and/or
\end{abstract}

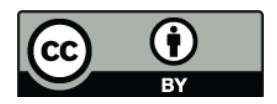

Correspondence to: G. P. Stiller (gabriele.stiller@imk.fzk.de) upward transport during fall in October/November $(\mathrm{NH})$ and April/May (SH), respectively, with small latitudinal gradients, immediately before the new polar vortex starts to form. The mean age distributions further confirm that $\mathrm{SF}_{6}$ is destroyed in the mesosphere to a considerable degree. Model calculations with the Karlsruhe simulation model of the middle atmosphere (KASIMA) chemical transport model agree well with observed global distributions of the mean age only if the $\mathrm{SF}_{6}$ sink reactions in the mesosphere are included in the model.

\section{Introduction}

According to model predictions, climate change is expected to intensify the Brewer-Dobson circulation (e.g. Buchart et al., 2006; Austin and Li, 2006). This would mean that stratospheric air will become younger within a global warming scenario, providing feedback to stratospheric chemistry, e.g. the chlorine load (Waugh et al., 2007; Waugh and Hall, 2002). A measure of the transport time of an air parcel travelling from the tropopause to a certain location in the stratosphere is the so-called age of stratospheric air (Kida, 1983; Waugh and Hall, 2002). Due to mixing, an air parcel consists of air of different ages, characterized by its age spectrum (Waugh and Hall, 2002). The average over the age distribution is known as the mean age of stratospheric air, $\Gamma$. Austin and Li (2006) have demonstrated that the mean age of stratospheric air is a suitable measure for the intensity of the Brewer-Dobson circulation or the upwelling flux. The mean age of air is lowest near the tropical tropopause and increases both with latitude and altitude (Waugh and Hall, 2002), reflecting the respective travelling times in the

Published by Copernicus Publications on behalf of the European Geosciences Union. 
global circulation. The mean age of stratospheric air can be derived from trace species which are stable within the troposphere and stratosphere and have a considerable trend which is, in the ideal case, linear. One suitable tracer for the measurement of the mean age of stratospheric air is sulphur hexafluoride $\left(\mathrm{SF}_{6}\right)$. It is produced almost entirely anthropogenically (Ko et al., 1993), has a well documented tropospheric increase and is chemically inert in the troposphere and stratosphere. The tropospheric increase has been linear for the last years and was consistent to a quadratic growth rate, with a very small quadratic term, however, before 1996 (Geller et al., 1997). The only sinks to be considered are photolysis and electron capture reactions in the mesosphere (Morris et al., 1995; Ravishankara et al., 1993; Reddmann et al., 2001) leading to atmospheric lifetimes of several hundreds to thousands of years (Ravishankara et al., 1993; Morris et al., 1995). The mean age of air derived from $\mathrm{SF}_{6}$ is generally in good agreement with that inferred from other tracers except in the polar vortices where intrusions of $\mathrm{SF}_{6}$ depleted mesospheric air may play a role (Waugh and Hall, 2002). The mean age of air derived from $\mathrm{SF}_{6}$ and not corrected for the mesospheric loss is sometimes referred to as the "apparent" mean age; whenever in this paper mean age of air derived from measured $\mathrm{SF}_{6}$ is mentioned, the apparent mean age is meant.

Measurements of $\mathrm{SF}_{6}$ and the mean age, in particular in the stratosphere, have been rather sparse until now. Longterm surface in situ and flask measurements from numerous sites are provided by the National Oceanic and Atmospheric Administration (NOAA) Earth System Research Laboratory (ESRL), Global Monitoring Division (GMD) via ftp://ftp.cmdl.noaa.gov/hats/sf6/. An airborne data set measured during various NASA ER-2 flights during the period 1992-1997 provided the most comprehensive stratospheric data set for $\Gamma$ derived from $\mathrm{CO}_{2}$ and $\mathrm{SF}_{6}$ observations covering all latitudes between $85^{\circ} \mathrm{N}$ and $60^{\circ} \mathrm{S}$, but only at one altitude (Boering et al., 1996; Elkins et al., 1996). Besides these observations, few vertical profiles from balloon-borne and airborne in situ and cryosampler instruments exist (Andrews et al., 2001; Strunk et al., 2000; Ray et al., 1999, 2002; Volk et al., 1997; Engel et al., 2006a,b). A few spectroscopic measurements of $\mathrm{SF}_{6}$ in the infrared have been performed from the ground (Zander et al., 1991; Rinsland et al., 2003) and from the space-borne instruments ATMOS on the Space Shuttle (Rinsland et al., 1990; Zander et al., 1992; Rinsland et al., 1993) and ACE-FTS on SCISAT (Rinsland et al., 2005).

Recently Burgess et al. $(2004,2006)$ provided first global datasets of $\mathrm{SF}_{6}$ from Michelson Interferometer for Passive Atmospheric Sounding/Environmental satellite (MIPAS/Envisat) spectral observations. They used MIPAS spectral data versions 4.53 to 4.59 (so-called "near-real time (NRT)" spectral data) for their analyses. The $\mathrm{SF}_{6}$ global distributions revealed the main expected features, however, they were biased low by approximately 0.4 pptv compared to the NOAA/ESRL/GMD surface flask measurements. To our knowledge, no attempt has been made to derive the mean age of stratospheric air from this data set so far.

In this paper, we present an alternative approach to retrieve $\mathrm{SF}_{6}$ from MIPAS/Envisat spectral data. Our data analysis is based on MIPAS high resolution spectra (ESA data version 4.61/62, so-called "re-processed" spectra) obtained from September 2002 to March 2004. After the description of the retrieval approach and the data characterization in terms of vertical resolution and error budget, global distributions of $\mathrm{SF}_{6}$ are presented. We validate individual profiles by comparison to balloon-borne in situ observations. The tropical tropospheric yearly increase is derived and compared to NOAA/ESRL/GMD surface in situ and flask measurements. The trend derived from the MIPAS measurements in combination with the long running NOAA/ESRL/GMD time series has been applied to infer the global distribution of mean age of stratospheric air, $\Gamma$. These data are compared to earlier observations, and their variation with time, altitude and latitude is analysed. Finally we address the importance of the mesospheric sink for age of air assessments from $\mathrm{SF}_{6}$.

\section{MIPAS}

The Michelson Interferometer for Passive Atmospheric Sounding (MIPAS) is a mid-infrared Fourier transform limb emission spectrometer designed and operated for measurement of atmospheric trace species (Fischer et al., 2007). Its spectral resolution in its original measurement mode was $0.035 \mathrm{~cm}^{-1}$, corresponding to an effective spectral resolution of $0.05 \mathrm{~cm}^{-1}$ after numerical apodization with the Norton Beer "strong" apodization function (Norton and Beer, 1976). It operated in this mode from March 2002 to March 2004. MIPAS is operated on the Envisat polar orbiting satellite and records a rear-viewing limb sequence of 17 spectra each $90 \mathrm{~s}$, corresponding to an along track sampling of approximately $500 \mathrm{~km}$ and providing about 1000 vertical profiles per day along 14 orbits in its original observation mode. The vertical tangent altitude spacing is $3 \mathrm{~km}$ between $6 \mathrm{~km}$ and $42 \mathrm{~km}$, which is the altitude range relevant to this study. The raw signal is processed by the European Space Agency (ESA) to produce calibrated geolocated limb emission spectra, labelled level 1-B data (Nett et al., 1999). After an instrument failure in March 2004, MIPAS resumed operation in a reduced spectral resolution mode with a variety of scan patterns providing different altitude coverage, horizontal and vertical sampling. For this study, level 1-B version 4.61/62 data (so-called "reprocessed" data) from September 2002 to March 2004 have been used. 


\section{$3 \mathbf{S F}_{6}$ retrieval}

\subsection{Retrieval strategy}

Retrievals presented here were carried out with the scientific MIPAS level 2 processor developed and operated by the Institute of Meteorology and Climate Research (IMK) in Karlsruhe together with the Instituto de Astrofísica de Andalucía (IAA) in Granada. The general retrieval strategy, which is a constrained multi-parameter non-linear least squares fitting of measured and modelled spectra, is described in detail in von Clarmann et al. (2003a,b). For radiative transfer modelling, the Karlsruhe Optimized and Precise Radiative transfer Algorithm (KOPRA) (Stiller et al., 2002) has been used. Only aspects of specific interest in the context of the retrieval of $\mathrm{SF}_{6}$ are discussed here.

The most suitable $\mathrm{SF}_{6}$ signature in the mid infrared spectrum is the Q-branch of the $v_{3}$ band at $947.9 \mathrm{~cm}^{-1}$. The suitability of this band was first demonstrated by Rinsland et al. (1990). Also, all space-borne measurements of $\mathrm{SF}_{6}$ that we are aware of rely on this band (ATMOS, ACE-FTS). In particular, Burgess et al. $(2004,2006)$ used spectral ranges from 929 to $931 \mathrm{~cm}^{-1}$ and 940 to $952 \mathrm{~cm}^{-1}$ for their $\mathrm{SF}_{6}$ retrievals from MIPAS/Envisat. The main interfering species are $\mathrm{CO}_{2}$, $\mathrm{H}_{2} \mathrm{O}$, and $\mathrm{NH}_{3}$. The peak of the $\mathrm{SF}_{6}$ signature is located at the near wing of the $\mathrm{CO}_{2}$ fundamental band (FB; $00011 \rightarrow$ 10001) laser line at $947.74 \mathrm{~cm}^{-1}$ and just above the first hot band (FH; $01111 \rightarrow 11101$ ) laser line at $947.94 \mathrm{~cm}^{-1}$. Spectroscopic data from the dedicated MIPAS data base (Flaud et al., 2003) which is largely identical to the HITRAN 2004 data base (Rothman et al., 2005) has been used. In particular, temperature- and pressure-dependent $\mathrm{SF}_{6}$ absorption cross sections for the spectral range 925 to $955 \mathrm{~cm}^{-1}$ and covering the atmospheric conditions of 180 to $295 \mathrm{~K}$ and 20 to 760 torr as provided by Varanasi et al. (1994) have been applied. It turned out that modelling of the line shapes of the interfering lines is extremely important for correct $\mathrm{SF}_{6}$ retrievals. For this reason, several actions have been taken to improve the modelling of the spectral vicinity of the $\mathrm{SF}_{6}$ band and these will be described in the following paragraphs.

Scattering of tropospheric radiance into the MIPAS line of sight by cloud particles was shown by Höpfner et al. (2002) to have a considerable effect on the spectral line shapes, particularly in the spectral region relevant to the $\mathrm{SF}_{6}$ retrieval. For this reason, specific care has been taken to exclude all spectra of particle-contaminated scenes from the data analysis. Rejection of cloud/aerosol contaminated MIPAS spectra was performed according to the colour ratio method of Spang et al. (2004) who used the ratio of the spectral regions 788.2$796.25 \mathrm{~cm}^{-1}$ and $832.3-834.4 \mathrm{~cm}^{-1}$, the so-called cloud index CI, to detect a cloud/aerosol signal in the spectra. In our study, a very rigorous cloud index of 6 , which reliably excludes any spectra contaminated by cloud signal (Glatthor et al., 2006), has been applied (i.e. all spectra having a cloud index of 6 or lower have been excluded from the retrievals).
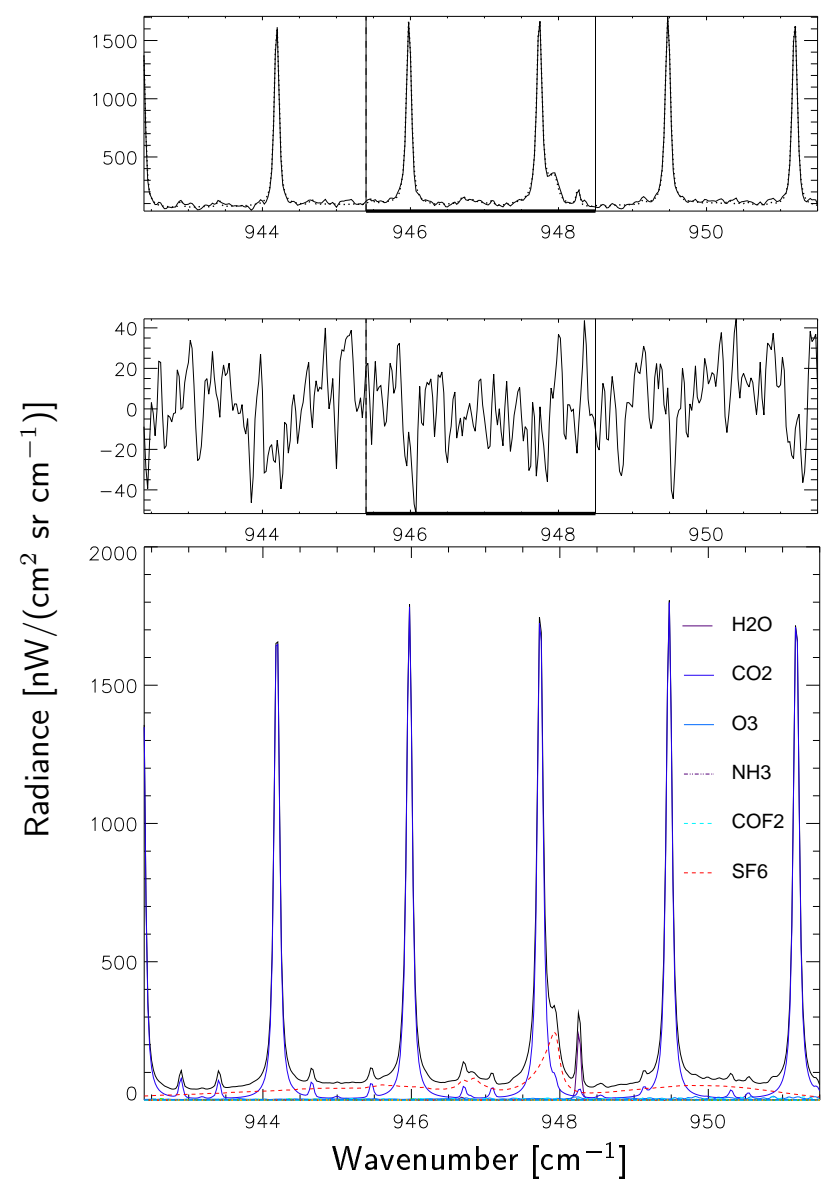

Fig. 1. Typical MIPAS spectrum (measured on 5 November 2003 at $12 \mathrm{~km}$ tangent altitude) (top), residual differences between measurement and best-fit spectrum (middle), and trace species spectral contributions (bottom). The bold horizontal line together with the vertical lines in the top two panels indicate the spectral range used within the retrievals. Main contributors are $\mathrm{SF}_{6}$ (bold dashed red), $\mathrm{CO}_{2} \mathrm{FB}$ laser band (blue, large spectral lines) and $\mathrm{CO}_{2} \mathrm{FH}$ laser band lines (blue, small spectral lines), and water vapour (violet).

Prior to the retrieval of $\mathrm{SF}_{6}$ volume mixing ratios (vmrs), the following quantities were retrieved and the resulting profiles were used as a priori information in the $\mathrm{SF}_{6}$ retrievals: residual spectral shift, instrument line shape correction, temperature and line of sight (von Clarmann et al., 2003b), and ozone. $\mathrm{NH}_{3}$ and $\mathrm{COF}_{2}$ emissions were also considered in the radiative transfer modelling, using climatological profiles for these trace species (Kiefer et al., 2002). The spectral range used for $\mathrm{SF}_{6}$ retrieval was $945.4 \mathrm{~cm}^{-1}$ to $948.5 \mathrm{~cm}^{-1}$ (see Fig. 1). Simultaneously with $\mathrm{SF}_{6}, \mathrm{CO}_{2}$ and $\mathrm{H}_{2} \mathrm{O}$ vmrs were retrieved in a multi-parameter retrieval approach. Beyond this, the background continuum emission and zero radiance calibration correction were retrieved jointly. The rationale of this approach is discussed in detail in von Clarmann et al. (2003b). 

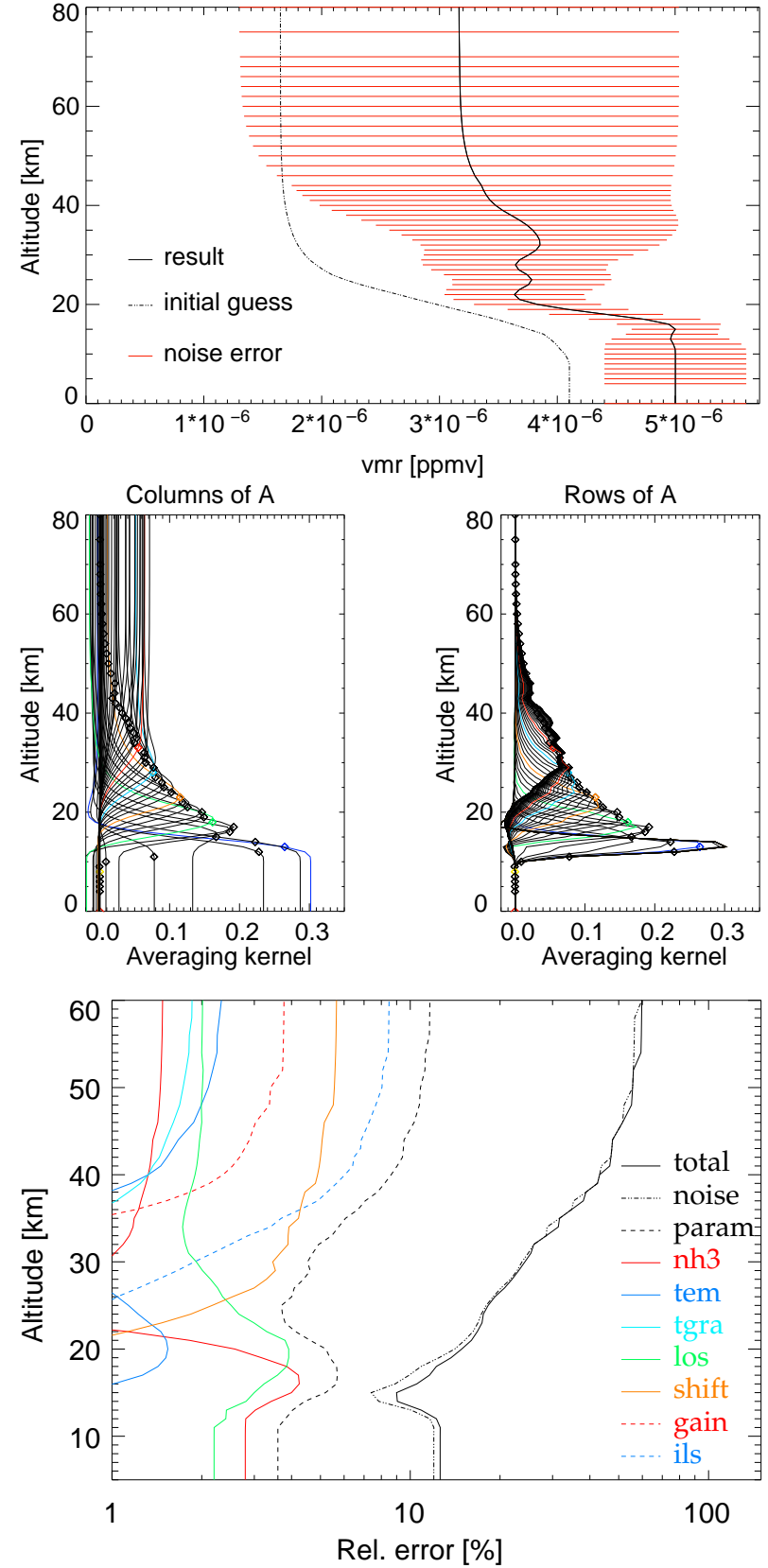

Fig. 2. Typical profile (top), columns and rows of the averaging kernel (middle), and relative error budget (in percent) (bottom), for a measurement of 5 November 2003. All spectra below $12.7 \mathrm{~km}$ have been excluded from the retrieval because of cloud contamination (cloud index less than or equal to 6). Error sources assessed are measurement noise (noise), the uncertainties in temperature (tem), line-of-sight (los) (from preceding retrievals), $\mathrm{NH}_{3}$ (nh3)(from climatological variability), and horizontal temperature gradients (tgra), residual uncertainties in radiometric (gain) and frequency shift calibration (shift), and residual uncertainties in the instrumental line shape (ils). The quadratic sum of all errors except measurement noise is given by the black dashed line (param), while the quadratic sum over all error sources is given by the black solid line (total).
In the vicinity of the $\mathrm{SF}_{6}$ signatures non-local thermodynamic equilibrium (non-LTE) effects are an important issue for the $\mathrm{CO}_{2}$ lines (López-Puertas and Taylor, 2001). To correct for these non-LTE emissions, but to keep the computational effort reasonably low, the $\mathrm{CO}_{2}$ lines of the $\mathrm{FB}$ and the FH laser band, respectively, have been modelled in a firstorder approach by retrieving a $\mathrm{CO}_{2}$ pseudo-vmr, i.e. a volume mixing ratio which, under LTE assumption, causes the same emission as the true $\mathrm{CO}_{2} \mathrm{vmr}$ under non-LTE. Since the two relevant bands are differently affected by non-LTE effects, the lines of the two bands were handled formally as if they belonged to different trace species. In order to constrain the $\mathrm{CO}_{2}$ line of the $\mathrm{FH}$ laser band just below the $\mathrm{SF}_{6}$ signature, further lines of the same band near $945.4 \mathrm{~cm}^{-1}$, $946.7 \mathrm{~cm}^{-1}$, and $947.1 \mathrm{~cm}^{-1}$ were also fitted. An example of measured and best-fit spectra, together with the assignment of the trace species spectral signatures is shown in Fig. 1. Due to non-linearity effects in radiative transfer, adjusting the vmrs to fit a spectral line instead of adjusting the nonLTE vibrational populations of the molecular states is only an approximation. The systematic errors introduced by this approach are discussed in Sect. 3.2.

The retrieval is performed on an altitude grid of $1 \mathrm{~km}$ step widths up to $44 \mathrm{~km}$ and $2-20 \mathrm{~km}$ steps above, and is regularized by a Tikhonov-type constraint which adds to the objective function of the least squares fit a penalty which keeps the differences of mixing ratios at adjacent altitudes reasonably small (Tikhonov, 1963; Steck and von Clarmann, 2001; Steck, 2002). This is achieved by using a smoothness constraint matrix of the type $\gamma \mathbf{L}_{1}^{\mathbf{T}} \mathbf{L}_{\mathbf{1}}$ where $\gamma$ is a scaling factor and $\mathbf{L}_{\mathbf{1}}$ is a first order finite differences operator. The use of the latter does not constrain the column information but only how this information is distributed over altitude and, thus, provides a bias-free retrieval. A typical profile is presented in Fig. 2, upper panel, together with its uncertainties due to measurement noise. The regularization strength has been adjusted such that about 4 degrees of freedom are obtained within the altitude range $8-35 \mathrm{~km}$, resulting in a vertical resolution of $4 \mathrm{~km}$ near the tropopause and $8 \mathrm{~km}$ above $35 \mathrm{~km}$ (see Fig. 2, middle panel). In order not to introduce any artifacts in the profile structure, an all-zero flat a priori profile has been used, which acts, along with the first order differences regularization operator, only as a smoothing constraint. Initial guess profiles in our retrievals are distinct from the a priori profiles and stem from a climatology (Kiefer et al., 2002). Since we iterate until convergence is achieved, the initial guess profiles have no influence on the results.

Error estimation is based on linear theory as suggested by Rodgers (2000). The error budget of the profile in Fig. 2 is provided in the third panel. The error budget includes the mapping of the measurement noise on the retrieved volume mixing ratios as well as the propagation of uncertainties of model parameters onto the result. Up to approximately $25 \mathrm{~km}$, the total uncertainty in the $\mathrm{SF}_{6} \mathrm{vmr}$ profiles is 0.4 to $0.5 \mathrm{pptv}$ ( 9 to $17 \%$ ), with the measurement noise as the 
dominating error source.

Additional contributions to model parameter errors were found to be uncertainties in temperature (tem), line-of-sight (los) (from preceding retrievals), $\mathrm{NH}_{3}$ (nh3) (from climatological variability), horizontal temperature gradients (tgra), residual uncertainties in radiance (gain) and frequency shift calibration (shift), and residual uncertainties in the instrumental line shape (ils). The main model parameter error contributions, however also of random nature, are the uncertainties due to the interference of $\mathrm{NH}_{3}$ lines for which the atmospheric volume mixing ratio is unknown, and the residual line-of-sight uncertainty. The only non-negligible systematic error source besides the spectroscopic uncertainty (reported to be a few percent (Nemtchinov and Varanasi, 2003)), is the residual instrumental line shape uncertainty which contributes with approximately $5 \%(0.2$ to $0.3 \mathrm{pptv})$ to the overall error budget above $30 \mathrm{~km}$. Typically, we use data sets from at least three observational days representing one month of measurements to construct zonal mean distributions which provide, for $5^{\circ}$ latitude bins, roughly 100 observations per bin, reducing the $\mathrm{SF}_{6}$ standard error of the mean to $1 \%$.

The error estimation does not include the smoothing error, nor the mapping of the smoothing error of joint fit parameters onto the $\mathrm{SF}_{6}$ profile, since both of these errors require robust knowledge of the true covariance matrices of these species (Rodgers, 2000), which is, to our judgment, not available.

\subsection{Consideration of non-LTE emissions for interfering} $\mathrm{CO}_{2}$ lines

As described above, the handling of differing non-LTE effects for $\mathrm{CO}_{2}$ lines from different spectroscopic bands has been treated by a simplified approach. In order to assess the systematic error potentially introduced by this approach, a limited data set (covering two days in November 2003 and January 2004) was treated with a non-LTE approach for the $\mathrm{CO}_{2} \mathrm{FB}$ and $\mathrm{FH}$ laser band lines using pre-calculated populations of the respective $\mathrm{CO}_{2}$ molecular states. These have been derived within the preceding retrieval of $\mathrm{CO}$ for the respective days, since the $\mathrm{CO}$ retrieval requires full $\mathrm{CO}_{2}$ nonLTE modelling (Funke et al., 2007), using the GRANADA non-LTE model (Funke et al., 2001).

The non-LTE emissions of the $\mathrm{CO}_{2}$ lines then were modelled by making use of the non-LTE functionality of the radiative transfer model KOPRA (Stiller et al., 2002) implemented in the scientific IMK/IAA MIPAS data processor.

The simplified approach and the full non-LTE treatment (see Fig. 3) of the $\mathrm{CO}_{2}$ lines, respectively, led to different simulations of the $\mathrm{CO}_{2}$ emission signatures in the spectral fits, and, in turn, to systematic $\mathrm{SF}_{6}$ differences. Comparison of both approaches revealed, for both example days, a high bias in $\mathrm{SF}_{6} \mathrm{vmr}$ for the simplified approach (0 to $0.1 \mathrm{pptv}$ or 0 to $+2 \%$ ) between 10 and $20 \mathrm{~km}$ (tropics) and 15 and
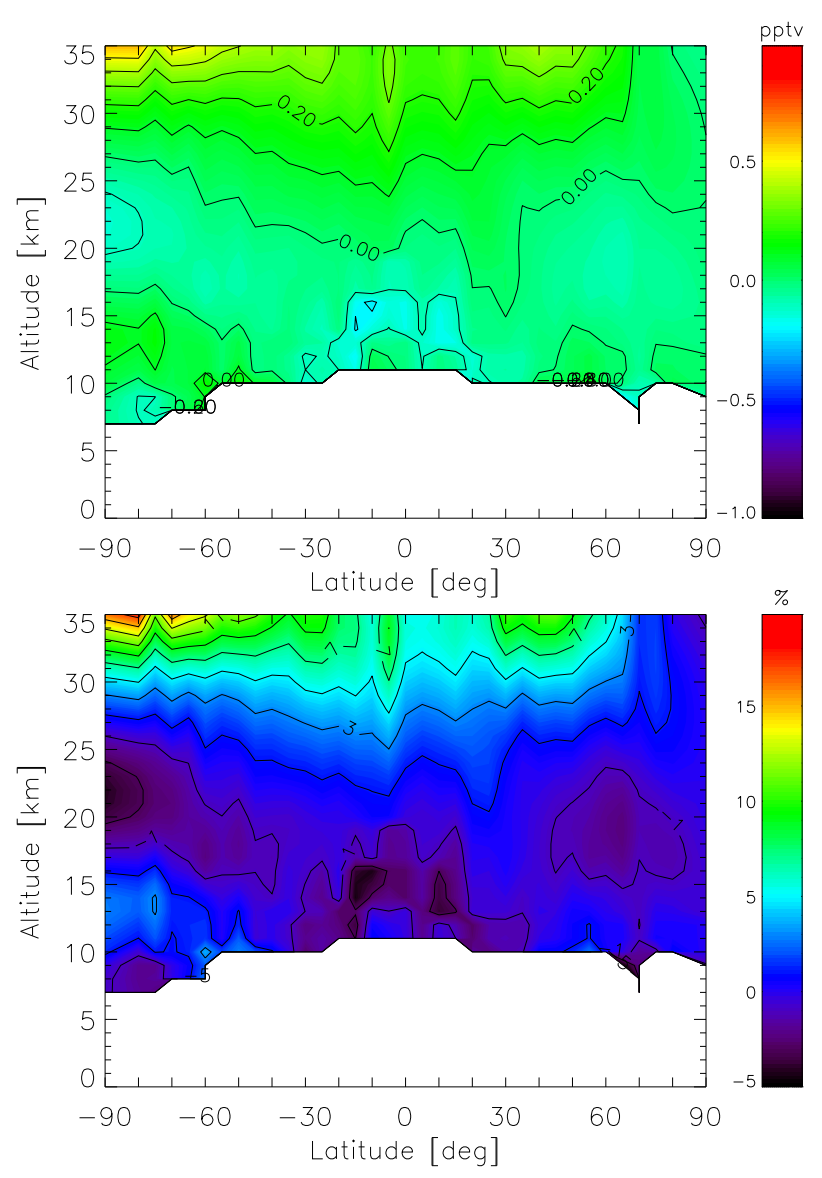

Fig. 3. Mean differences of $\mathrm{SF}_{6} \mathrm{vmr}$ profiles (top: absolute in pptv, bottom: relative in percent) between the retrieval which fully considers $\mathrm{CO}_{2}$ non-LTE emissions and the standard retrieval (non-LTE - standard) for 1 January 2004. Percentage differences are given relative to the retrieval which fully considers $\mathrm{CO}_{2}$ non-LTE emissions, i.e. (non-LTE - standard)/non-LTE is shown. The $5^{\circ}$ latitudinal mean differences for a full day of observations (1000 scans in total distributed within 35 latitude bands) are provided. White areas are missing data due to clouds.

$25 \mathrm{~km}$ (high latitudes) and a low bias ( 0 to $-0.2 \mathrm{pptv}$ or 0 to $-4 \%$ ) at 25 to $35 \mathrm{~km}$ altitude. The $\mathrm{SF}_{6}$ low bias is most pronounced, with values of $0.5 \mathrm{pptv}$ or higher, above $35 \mathrm{~km}$ over the summer pole due to the prevailing illumination, keeping in mind that the $\mathrm{CO}_{2}$ non-LTE effects are mainly due to solar excitation.

This means that inferred mean age of air (on the basis of a trend of $0.22 \mathrm{pptv}_{\mathrm{yr}^{-1}}$ ) is expected to be 0 to 0.5 years too low in the lower stratosphere and 0 to 1 year too high above $25 \mathrm{~km}$; a maximum bias of up to 2 years is reached at the summer pole above $35 \mathrm{~km}$ only, an altitude range which is not used in this study, and not recommended to be used in other studies, for the assessment of the mean age of air. Since this effect, although of systematic nature, has no simple altitude and latitude relationship, we have not corrected 
the data set and use original uncorrected data for our study. Re-processing of the complete data set in order to eliminate the bias was not possible at this time due to missing $\mathrm{CO}_{2}$ vibrational temperatures (provided from $\mathrm{CO}$ retrievals) for most of the days included in this analysis.

\subsection{Effects and handling of imperfect gain calibration}

Peculiar high day-to-day variability in global $\mathrm{SF}_{6}$ distributions provided another hint towards a systematic error in the data. It turned out that the $\mathrm{SF}_{6}$ retrievals were extremely sensitive to very small systematic oscillations in the radiance baseline, affecting the shape of the $\mathrm{SF}_{6}$ signature itself and that of interfering lines. These baseline oscillations are well below the NESR (Noise Equivalent Spectral Radiance) specification of MIPAS and become visible only after averaging a huge number of spectra. Nevertheless, the $\mathrm{SF}_{6}$ retrievals, at least above 20 to $25 \mathrm{~km}$, are systematically affected by these oscillations, which occur in the version 4.61 spectra only. These radiance baseline oscillations are of different nature than the gain error listed in the error budget (see Fig. 2). The latter is the uncertainty of the scaling of the spectrum. A method to quantify the systematic contribution to the $\mathrm{SF}_{6}$ retrievals and to correct the $\mathrm{SF}_{6}$ distributions for this contribution has been developed and applied to the data set presented in this study. Technical details about the correction method are given in the Appendix. For further use, daily and monthly zonally averaged $\mathrm{SF}_{6}$ data have been corrected for the systematic contributions from the radiance baseline oscillations according to the method described in the Appendix. All daily and monthly averages of $\mathrm{SF}_{6} \mathrm{vmrs}$ and age of air data presented in the following sections are corrected for the bias caused by the radiance baseline oscillations (called gainbias in the following).

\section{Comparison to balloon-borne cryo-sampler data}

During the first observation phase of MIPAS from July 2002 to March 2004 several field campaigns took place, some of them intended for validation of Envisat instruments. The balloon-borne cryogenic whole-air sampler BONBON (Engel et al., 2006b) which provides highly accurate data, measured during three balloon flights, one on 24 September 2002 in Southern France, the other two on 6 March 2003 and 9 June 2003 near Kiruna, Sweden. Figure 4 presents the comparison of co-incident MIPAS profiles with the in situ data, together with a map showing the locations, the temporal and spatial mis-matches and the potential vorticity (PV) fields. For close co-incidences, the MIPAS profiles agree with the BONBON data to within 0.5 pptv below $25 \mathrm{~km}$ which is fully consistent with the estimated error budget. For 24 September 2002, the gain-bias corrected profiles are also shown; the gain-bias for this day is one of the smaller ones, but not negligible.

\section{Global $\mathrm{SF}_{6}$ distributions}

Global $\mathrm{SF}_{6}$ distributions using gain-bias corrected data have been derived for the period September 2002 to March 2004 for at least 3 days per month. Figure 5 shows the $5^{\circ}$ zonally averaged global distribution for March 2003. For each $5^{\circ}$ latitude bin, approximately 140 individual profiles have been averaged, leading to a mean value standard error in the order of 0.05 pptv or $1 \%$. The zonal mean distribution reveals all features expected from earlier observations: Tropospheric $\mathrm{SF}_{6}$ is homogeneously distributed with values between 5.0 and 5.5 pptv, but slightly higher in the Northern Hemisphere due to industrial sources. The $\mathrm{SF}_{6} \mathrm{vmr}$ decreases both with altitude and latitude, reflecting the time needed to transport air parcels from the tropical tropopause to higher altitudes and latitudes. The stratospheric $\mathrm{SF}_{6} \mathrm{vmr}$ over the spring pole is lowest since the aged polar vortex is filled with old air which might also have experienced $\mathrm{SF}_{6}$ depletion in the mesosphere. The seasonal and latitudinal variation of $\mathrm{SF}_{6}$ within the observational data set is shown in the electronic supplement (http://www.atmos-chem-phys.net/8/677/ 2008/acp-8-677-2008-supplement.pdf) as monthly zonal mean profiles (averaged for $5^{\circ}$ latitude bins) for various months and latitudes.

\section{Tropical tropospheric $\mathrm{SF}_{6}$ increase}

The temporal tropical tropospheric increase of MIPAS $\mathrm{SF}_{6}$ observations was derived from daily mean values averaged over $17.5^{\circ} \mathrm{S}$ to $17.5^{\circ} \mathrm{N}$ and 9 to $15 \mathrm{~km}$ (Fig. 6). The linear regression provides an increase of $0.230 \pm 0.008 \mathrm{pptv} / \mathrm{year}$ with an extrapolated value of 4.89 pptv on 1 January 2002 . This is in excellent agreement with globally averaged ground-based flask and in situ observations as provided by the NOAA/ESRL/GMD (data from ftp://ftp.cmdl.noaa.gov/ hats/sf6/insituGCs/CATS/global/insitu_global_SF6 and ftp:// ftp.cmdl.noaa.gov/hats/sf6/flasks/SF6global_2007.txt): The trend reported for NOAA/ESRL/GMD in situ global data is $0.224 \pm 0.002 \mathrm{pptv} / \mathrm{year}$, and for flask data it is $0.217 \pm 0.003 \mathrm{pptv} / \mathrm{year}$; both data sets provide a global mean of $4.88 \pm 0.03$ pptv for January 2002 (B. Hall, personal communication, 2007).

Although the NOAA/ESRL/GMD flask and in-situ data are ground-based measurements, while the MIPAS data represent the tropical middle to upper troposphere, we believe that such a comparison is well justified since we expect homogeneous mixing in the troposphere for a tracer like $\mathrm{SF}_{6}$ which has no tropospheric sinks. This assumption is confirmed by findings of Gloor et al. (2007). These authors present vertical profiles of tropospheric $\mathrm{SF}_{6}$ vmrs measured in-situ at various sites and seasons (see their Fig. 7). In general, their profiles agree very well with the assumption of constant values in the planetary boundary layer (PBL) and the free troposphere. The only site where $\mathrm{SF}_{6} \mathrm{vmrs}$ in the 

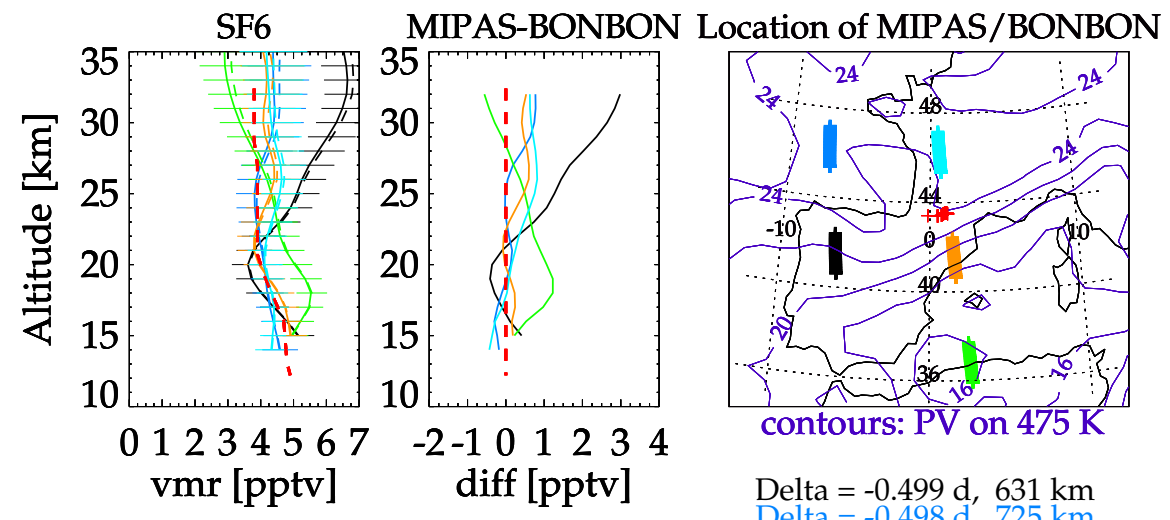

BONBON-flight on 20020924

Delta $=-0.499 \mathrm{~d}, 631 \mathrm{~km}$

Delta $=-0.498 \mathrm{~d}, 725 \mathrm{~km}$
Delta $=0.478 \mathrm{~d}, 738 \mathrm{~km}$

Delta $=0.479 \mathrm{~d}, 209 \mathrm{~km}$

Delta $=0.480 \mathrm{~d}, 321 \mathrm{~km}$

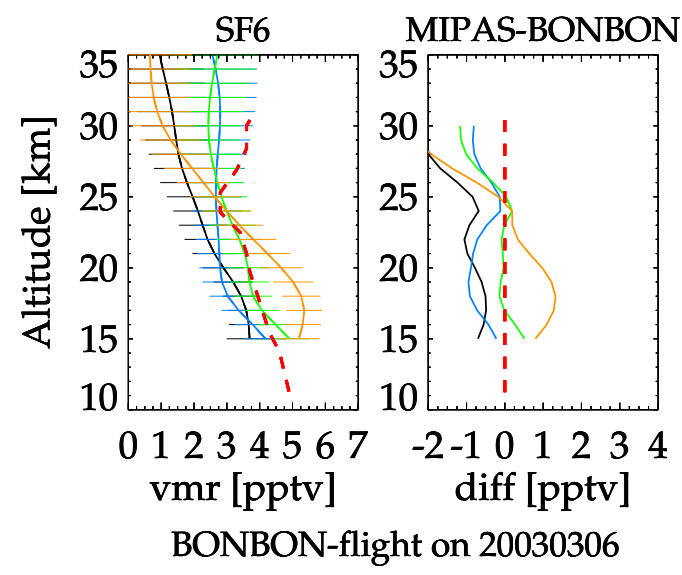

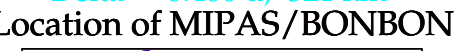

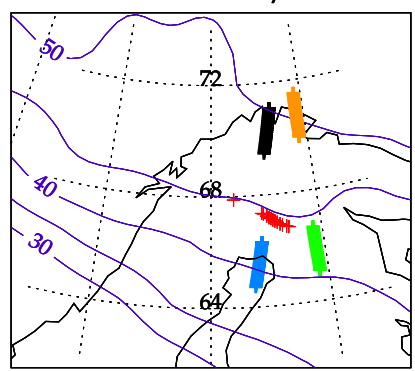

contours: PV on $475 \mathrm{~K}$

Delta $=-0.039 \mathrm{~d}, 333 \mathrm{~km}$

Delta $=-0.038 \mathrm{~d}, 213 \mathrm{~km}$

Delta $=0.441 \mathrm{~d}, 177 \mathrm{~km}$

Delta $=0.442 \mathrm{~d}, 459 \mathrm{~km}$

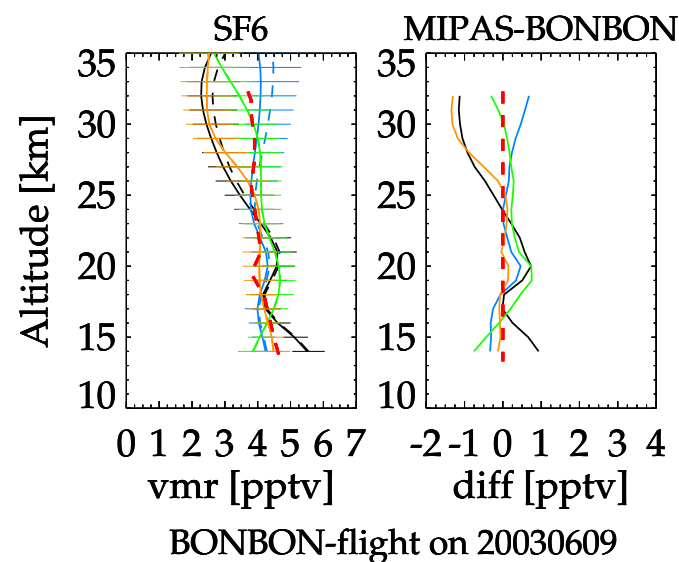

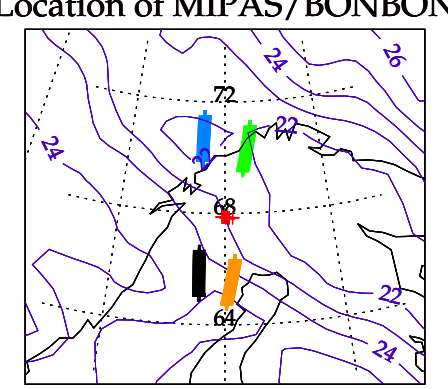

contours: PV on $475 \mathrm{~K}$

Delta $=-0.483 \mathrm{~d}, 218 \mathrm{~km}$

Delta $=-0.482 \mathrm{~d}, 347 \mathrm{~km}$

Delta $=0.015 \mathrm{~d}, 260 \mathrm{~km}$

Delta $=0.016 \mathrm{~d}, 288 \mathrm{~km}$

Fig. 4. Comparison of individual $\mathrm{SF}_{6}$ profiles with co-located in situ observations obtained during balloon flights of a cryogenic whole-air sampler (BONBON) (Engel et al., 2006b), for (top) 24 September 2002 over Southern France, and (middle) 6 March 2003 and (bottom) 9 June 2003 over Northern Scandinavia. The left panels show the profiles measured by MIPAS (colours except red) and BONBON (red) for the best co-incidences. The middle panels provide the difference profiles between MIPAS and BONBON. In the right panels the location of the observations are shown together with the PV contours on $475 \mathrm{~K}$ (violet contour lines, PV units: $\mathrm{K} \mathrm{m}^{2} \mathrm{~kg}^{-1} \mathrm{~s}^{-1}$ ) and the temporal and spatial distances. For the September 2002 flight, in addition the gain-bias corrected MIPAS observations are given (dashed coloured lines except red in the left panel). 


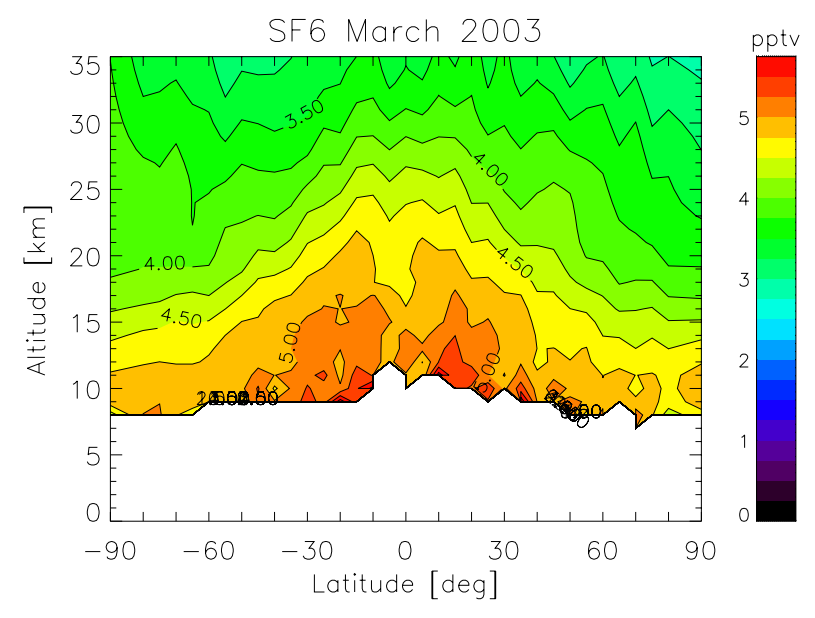

Fig. 5. Global mean distribution of $\mathrm{SF}_{6}$ (gain-bias corrected) for March 2003 (geographical latitude versus altitude, $5^{\circ}$ latitude bins; approximately 140 profiles per latitude bin). White areas are missing data due to clouds.

PBL were significantly higher than in the free troposphere was Harvard, Forest, Massachusetts (called HFM) which "is located near a strong emission region" (Gloor et al., 2007). In their Table 4, they present PBL - free troposphere differences in the order of -0.03 to $+0.05 \mathrm{pptv}$, (with one exception, again belonging to HFM where the difference is +0.22 pptv). Differences in the order of $0.025 \mathrm{pptv}$ (about $0.5 \%$ of the actual $\mathrm{SF}_{6} \mathrm{vmr}$ ) are below the standard error of the MIPAS daily tropical tropospheric mean values and just in the range of the standard error of the GMD ground-based in-situ data and would, thus, not be detectable in the comparison to GMD values. We conclude from the Gloor et al. (2007) paper that the bias between the PBL and the free troposphere is so small that it is not relevant within the MIPAS - NOAA/ESRL/GMD comparison.

The MIPAS-derived linear increase has been used to convert $\mathrm{SF}_{6}$ global distributions into mean age of stratospheric air by assigning the $\mathrm{SF}_{6} \mathrm{vmr}$ difference observed in the troposphere and at some location in the stratosphere, respectively, to the time lag since the troposphere had shown the mixing ratio measured in the stratosphere, according to the following linear relationship:

age $=t-t_{0}-\frac{\mathrm{SF}_{6}-a}{b}$

with $t=$ time of the observation (in years), $t_{0}=2002.0$ (i.e. 1 January 2002), $a=4.89 \mathrm{pptv}$ (the tropical tropospheric vmr on 1 January 2002 as derived from Fig. 6), $b=0.230 \mathrm{pptv} / \mathrm{yr}$ (the yearly tropical tropospheric increase as derived from Fig. 6).

By doing this we implicitly assume that the yearly increase of the tropical tropospheric $\mathrm{SF}_{6} \mathrm{vmr}$ as derived from MIPAS has remained linear and constant within the relevant period given by the actual ages observed in the atmosphere, i.e. for about 10 to 15 years. For about 8 years, this assumption is confirmed by the time series of ground-based

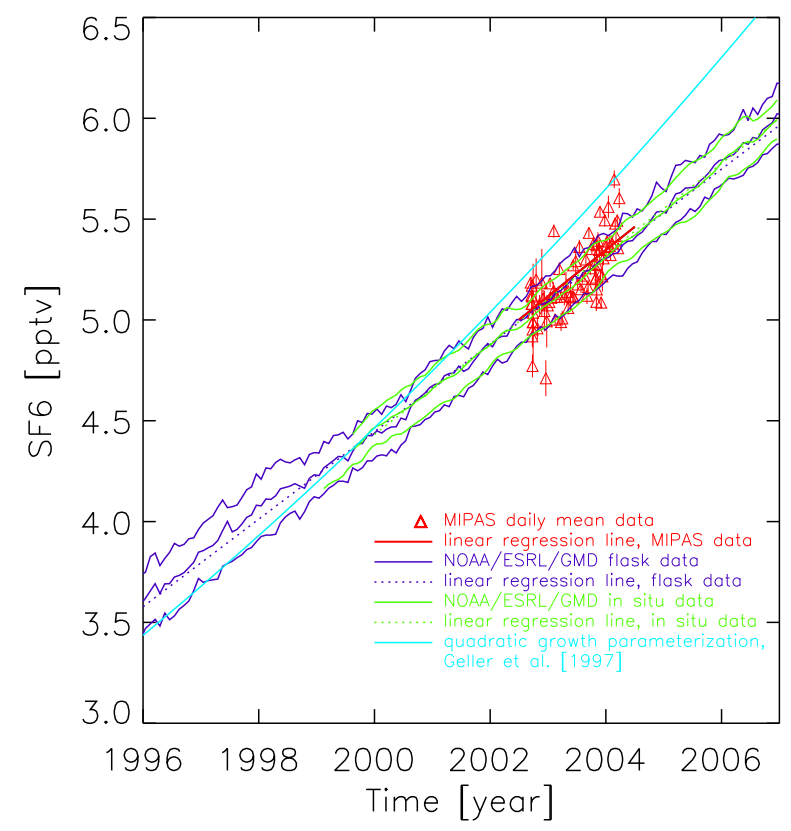

Fig. 6. Tropical tropospheric $\mathrm{SF}_{6}$ increase derived from the daily gain-bias corrected zonal mean distributions of $\mathrm{SF}_{6}$ within $17.5^{\circ} \mathrm{N}$ and $17.5^{\circ} \mathrm{S}$ and 9 to $15 \mathrm{~km}$ altitude (red symbols and red solid line; error bars are the $1 \sigma$ standard errors of the daily means). Time series of NOAA/ESRL/GMD flask measurements (violet) and in situ measurements (green) for the Northern Hemisphere (highest lines), global mean (middle lines), and Southern Hemisphere (lowest lines) are also shown, together with their regression lines for the global mean data (dotted green and violet lines). The light blue line extrapolates the growth parameterization derived by Geller et al. (1997) for the years 1987-1996 to the period 1996-2006. The trend

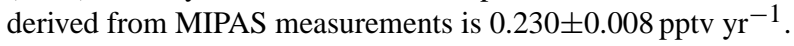

NOAA/ESRL/GMD measurements covering the years 1996 to 2006 , since the time series of the globally averaged $\mathrm{SF}_{6}$ vmr is well consistent with a linear increase (see Fig. 6, dotted lines). For the period 1987-1996, Geller et al. (1997) found that the surface $\mathrm{SF}_{6}$ increase was consistent with an overall quadratic growth rate, where the quadratic term, however, was rather small compared to the linear term (the coefficients are $0.0049 \mathrm{pptv} / \mathrm{yr}^{2}$ (quadratic term) vs. $0.2376 \mathrm{pptv} / \mathrm{yr}$ (linear term)), while Maiss and Levin (1994) found Southern hemispheric $\mathrm{SF}_{6}$ observations between 1970 and 1991 to be consistent with a purely quadratic increase described by $0.004763 \times(t-1968.82)^{2}$. The extrapolation of the Geller et al. (1997) parameterization to the 1996-2006 period is shown for comparison in Fig. 6 as light-blue line. It is obvious that the actual yearly increase in the 1996-2006 period is smaller and more linear than the 2nd order extrapolation from the previous 10 years. For the period 1987-1996, however, the extrapolation of the linear trends from MIPAS and NOAA/ESRL/GMD will overestimate the steepness of the $\mathrm{SF}_{6}$ increase, introducing a systematic error into the age-ofair assessment from these trends. 

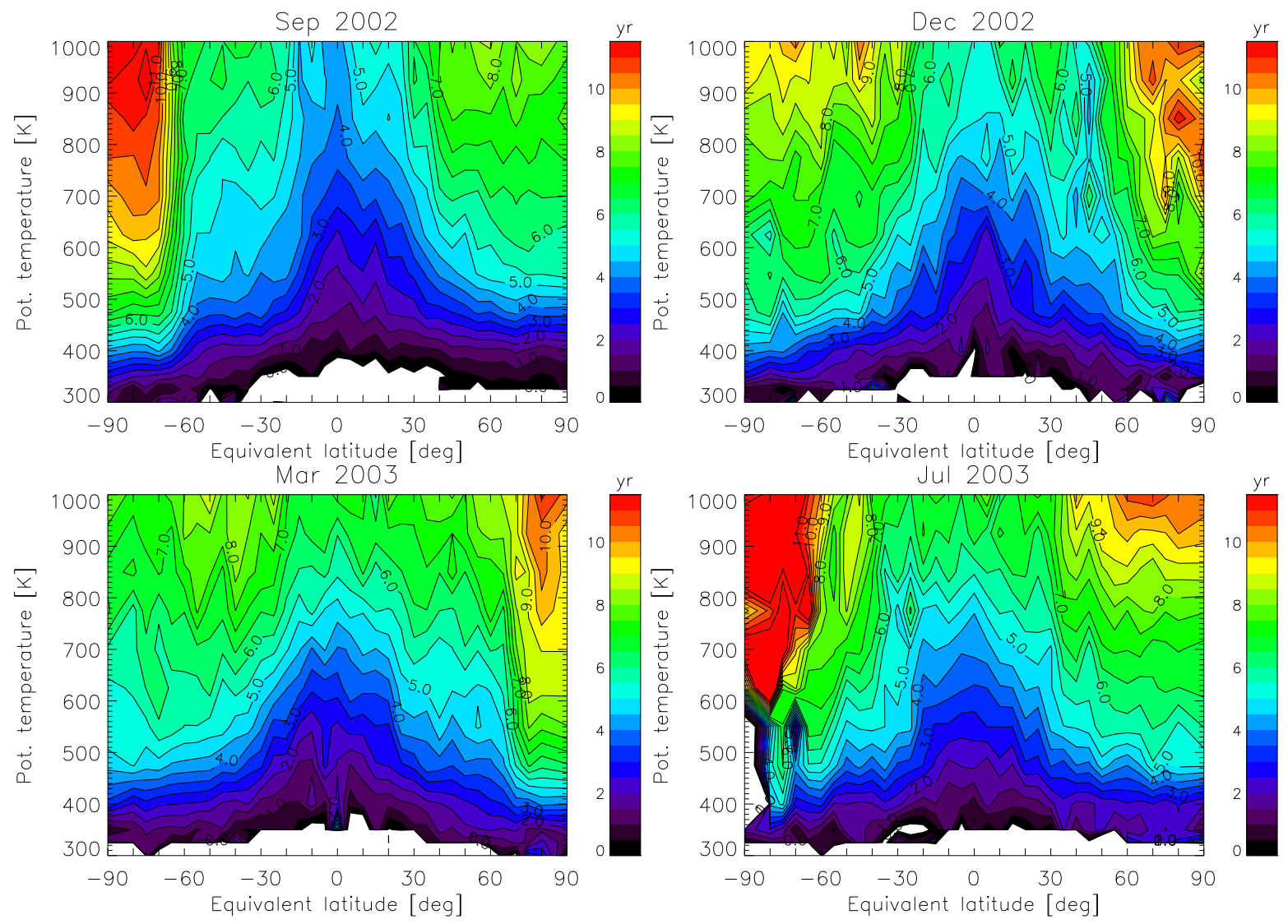

Fig. 7. Global distributions of mean age of stratospheric air (potential temperature versus equivalent latitudes) for the months September 2002 (top left), December 2002 (top right), March 2003 (bottom left), and July 2003 (bottom right).

If we assume that the $\mathrm{SF}_{6}$ increase is described well by the quadratic parameterization derived by Geller et al. (1997) for the period 1987-1996 and by the MIPAS-derived linear increase since 1996, and we use the MIPAS-derived linear increase for age-of-air assessment for ages between 6 and 15 years, we underestimate the inferred ages by at most 1.2 years, i.e. for 15 year old air the MIPAS linear increase would provide an age of 13.8 years. If we additionally correct the Geller et al. growth parameterization by an additive term of +0.14 pptv in order to better match the most recent NOAA/ESRL/GMD global mean flask data of 1 January 1996 (3.58 pptv, from the regression line), we estimate that the MIPAS linear trend will underestimate the inferred ages even by up to 1.7 years for 15 years of "real" age. However, one should keep in mind that $\mathrm{SF}_{6}$-derived ages higher than 6 to 8 years have been observed within polar vortices only; the respective low $\mathrm{SF}_{6}$ vmrs are due to intrusions of mesospheric air which had undergone mesospheric $\mathrm{SF}_{6}$ loss processes (see Sect. 7.3); the assessment of real age of air from these $\mathrm{SF}_{6}$ observations suffers from further uncertainties like the details of mesospheric loss modelling in chemistry transport models.
We used the MIPAS-derived increase instead the NOAA/ESRL/GMD trend in order to account for the small additive bias between MIPAS and the ground-based measurements which is apparent by the vertical shift of the MIPAS regression line (red solid line in Fig. 6) versus the NOAA/ESRL/GMD global mean time series (middle green and violet solid lines and dotted regression lines in Fig. 6).

\section{Mean age of stratospheric air}

\subsection{Global distributions}

The global distribution of the mean age of stratospheric air derived from MIPAS $\mathrm{SF}_{6}$ monthly zonal means (provided for potential temperature versus equivalent latitudes) is shown in Fig. 7 for the months September 2002, December 2002, March 2003, and July 2003. While ascent of young air is most pronounced over the tropics during the Northern Hemispheric fall and winter months (Fig. 7, top row), very old air is found for both polar winter vortices (top and bottom right panels). During fall (top and bottom left panels) in the respective hemisphere, the horizontal age gradients in the 

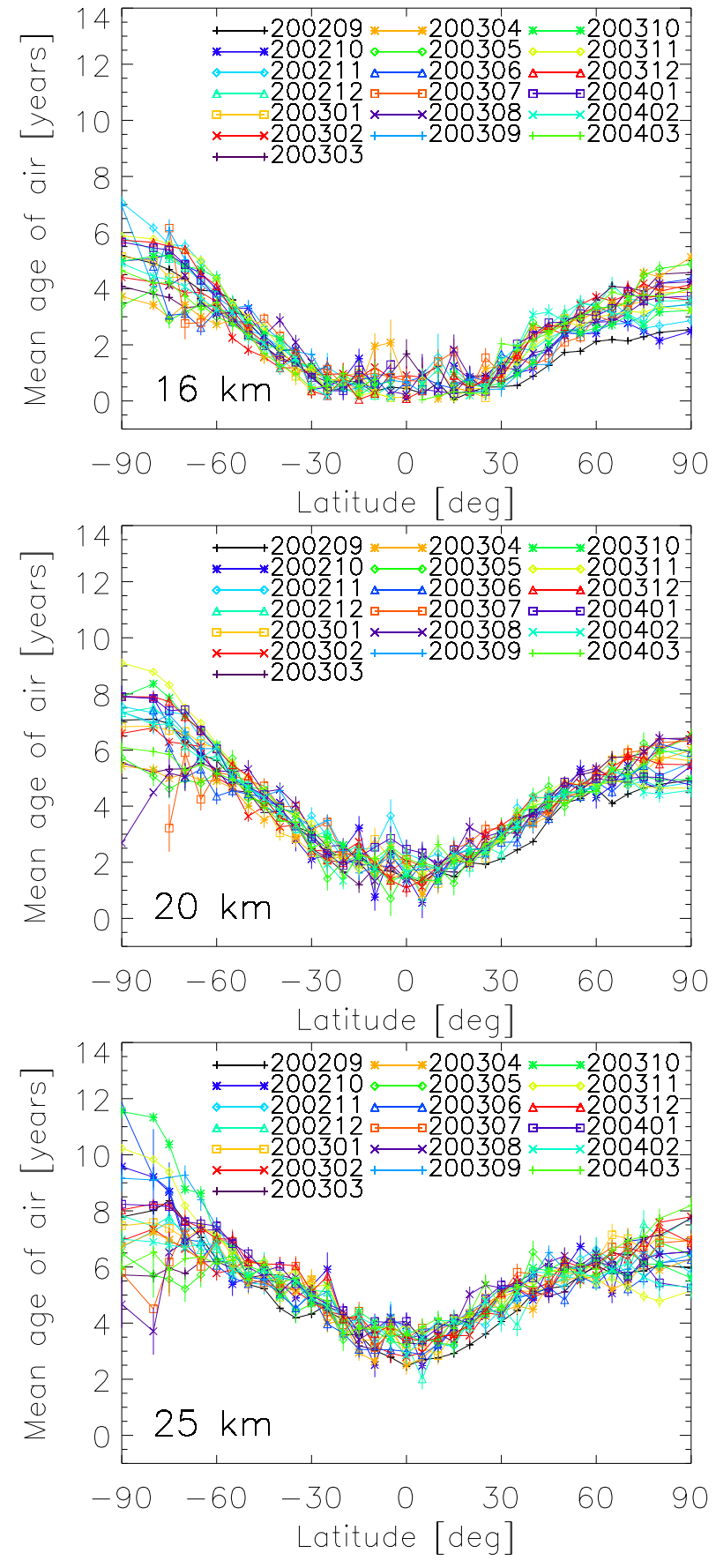

Fig. 8. Mean age of air at (top) $16 \mathrm{~km}$, (middle) $20 \mathrm{~km}$, and (bottom) $25 \mathrm{~km}$ altitude from MIPAS/Envisat $\mathrm{SF}_{6}$ distributions; presented are the monthly zonal means for $5^{\circ}$ latitude bins for all months between September 2002 and March 2004. The error bars represent the $1 \sigma$ standard errors of the mean.

middle stratosphere are lowest, providing ages typical for mid-latitudes also in the polar regions. During spring (top and bottom left panels) the surf zone in mid-latitudes is most pronounced revealing latitudinally nearly constant mean age of air in the lower to middle stratosphere, which is produced by isentropic mixing due to planetary waves.

The surf zone is separated from the tropics, and even more sharply separated from the polar vortex, by a barrier revealing very high horizontal age gradients. Also remarkable is the remnant of old air in the middle stratospheric summer above $850 \mathrm{~K}$ during December $2002(\mathrm{NH})$ and July (SH) (Fig. 7, top and bottom right panels).

A compilation of monthly zonally averaged age of air distributions at three different altitudes is shown in Fig. 8. In the tropics and mid-latitudes, the seasonal variation over the 19 months covered by our data is rather low. Similar figures are available from, e.g. NASA ER-2 observations of the mean age of air (see, for example, Waugh and Hall (2002), their Fig. 6); the MIPAS results can be compared directly with those and provide, additionally, data for the Southern Hemisphere polar region. For $20 \mathrm{~km}$ altitude, the tropical mean age of air from MIPAS is between 0.5 and 2.5 years while the ER-2 observations yield an age around 1 year. The mean age increases with latitude for both hemispheres, with a significant seasonal variation in the polar regions. During polar winter on the Northern Hemisphere, the highest MIPAS values are around 6 years, while near the South pole, the spread is considerably larger with $\mathrm{SF}_{6}$-derived apparent ages of up to 9.5 years in winter and spring. From the ER2 data set, Northern Hemispheric ages of up to 6 years, and $60^{\circ} \mathrm{S}$ ages up to 5.5 years were derived, which are consistent with our data set. Inter-annual differences are also noticeable (compare, for instance, September 2002 to September 2003). During September 2002 an unprecedented Southern hemispheric major warming took place, with very high planetary wave activity (Manney et al., 2005b) which might be reflected in the slightly unusual age of air distribution. For $16 \mathrm{~km}$ altitude (first panel of Fig. 8), i.e. just at the altitude of the tropical tropopause layer, the age of air in the tropics is between 0 and 1.5 years, as expected. For polar regions, ages between 2 and 5 years in the North and 3 to 7 years in the South are observed. For higher altitudes (e.g. $25 \mathrm{~km}$, third panel of Fig. 8) the tropical mean age of air is around 3 to 3.5 years, while the seasonal variation and inter-annual differences at the poles become even more pronounced; this suggests stronger impact of mesospheric intrusions at this altitude than lower down in the stratosphere (see below). The systematic bias in the present MIPAS age data set due to the $\mathrm{CO}_{2}$ non-LTE treatment (see Sect.3.2 and Fig. 3) should be kept in mind for these comparisons. A complete correction of this bias is not possible at the current state since its seasonal variation is not yet known. For Northern winter conditions (see Fig. 3), correction of the bias would increase the age of air at $16 \mathrm{~km}$ by about 0.5 years in the tropics and 0 to 0.5 years at other latitudes; it would not change the latitudinal distribution at $20 \mathrm{~km}$; and it would decrease the age of air by about 0.5 years for all latitudes at $25 \mathrm{~km}$.

Zonally averaged monthly mean profiles of mean age of air for several latitudes and months, similar to Waugh 
and Hall (2002), their Fig. 6, are provided in the electronic supplement (http://www.atmos-chem-phys.net/8/677/ 2008/acp-8-677-2008-supplement.pdf).

\subsection{Temporal variation}

The seasonal variation and inter-annual differences are most clearly displayed by time series of equivalent-latitude distributions at certain potential temperature levels (see Fig. 9) and those of vertical profiles (in terms of potential temperature as vertical coordinate) for certain equivalent-latitude bands (see Fig. 10). During Austral winter, extremely high apparent ages of 12 years or more, in fact unrealistically high, were observed at the $625 \mathrm{~K}$ surface and above (see Fig. 9 and Fig. 10, bottom panel) during two episodes (June to July 2003; September to November 2003), separated by an episode of younger air (August 2003). The first episode of high mean age started rather abruptly in June 2003; in July the polar vortex was filled with air older than 8 years, south of $70^{\circ} \mathrm{S}$ equivalent latitude for altitudes above the $675 \mathrm{~K}$ potential temperature level. After the break in August 2003, the latitude- and altitude regime filled up with old air even increased; this situation lasted until end of November. The Antarctic winter 2003 has been characterized from observations of CO (Funke et al., 2005) and $\mathrm{NO}_{\mathrm{x}}$ (Funke et al., 2005; Randall et al., 2007) by a very strong vortex with long-lasting and strong transport of mesospheric air into the stratospheric vortex. Hence, the very high apparent age of air observed is most probably due to $\mathrm{SF}_{6}$-depleted mesospheric air masses filling the stratospheric vortex. In contrast to the very longlasting area of old air masses in 2003, the very old air disappeared earlier in 2002, probably due to the weak vortex being perturbed frequently by planetary wave activity which finally led to the first observed Southern Hemispheric major warming (Manney et al., 2005b). Although very high ages were no longer observed during Southern summer, the mean age of air remained rather high even then, with values around 6 to 8 years. Only immediately before the formation of the next polar vortex, in April/May, ages closer to those typical for mid-latitudes were observed at high Southern latitudes, indicating that polar summer air was mixed with lower-latitude air.

The observed northern hemispheric winters 2002/2003 and 2003/2004 are rather different than the Southern hemispheric ones (2002 and 2003) since obvious subsidence episodes are shorter, and the high ages of the Southern hemispheric winters have not been observed (Fig. 9 and Fig. 10, top panel). At $625 \mathrm{~K}$, the highest age of air observed in the Northern winters during the measurement time of MIPAS is 8 to 9 years, in March 2003 and 2004; ages of 10 or more years are observed at $1000 \mathrm{~K}$ in December 2002, March 2003, January and March 2004, and, surprisingly, in July 2003. Intrusions of mesospheric air into the polar vortex during the Northern winter 2002/2003 are described in various papers (Konopka et al., 2007; Engel et al., 2006b). This seems to be confirmed by MIPAS age of air observations. However, although the 8-year isoline came down to about $550 \mathrm{~K}$ in December 2002, the mesospheric intrusion did obviously not last long enough to fill up the vortex with aged mesospheric air. Another extreme winter was the late winter 2004 (Manney et al., 2005a; Randall et al., 2006). During January to March 2004, strong subsidence of upper atmospheric $\mathrm{NO}_{\mathrm{x}}$ into the polar stratosphere has been observed by various instruments (Randall et al., 2006; Seppälä et al., 2007; Hauchecorne et al., 2007; Funke et al., 2008 ${ }^{1}$ ). This again is confirmed by the observed age of air, since ages of 8 years and more have been observed above $625 \mathrm{~K}$. However, despite severe subsidence events, similar high ages of air as for the Southern hemispheric winter 2003 have not been observed during the two Northern hemispheric winters covered by MIPAS (see Fig. 9). Considerable inter-hemispheric differences are also observed at high latitudes at the $400 \mathrm{~K}$ level (see Fig. 9, top left panel), with air again being much older in the Southern Hemisphere.

The age of air in the tropics at $400 \mathrm{~K}$ is rather constant over the seasons, except that a slight seasonal oscillation with latitudes can be observed. At 850 and $1000 \mathrm{~K}$, however, the tropical air is youngest in Northern winter 2002/2003, but even Northern winter 2003/2004 (December 2003 to February 2004) has younger air than the summer and fall months before, except June 2003. Observation of younger air at tropical high altitudes during northern winter months is consistent to the fact that the strongest ascent by the BrewerDobson circulation occurs during this time of the year. In June 2003, very young air (i.e. strong upwelling) is found in the tropics which might be related to the very old air at the South pole (strong subsidence), indicating a short episode of intensified circulation.

\subsection{Comparison to model calculations}

Observations of apparent age of air derived from $\mathrm{SF}_{6}$ vmrs of more than 6 to 8 years were also reported previously (Engel et al., 2006b; Hall and Waugh, 1998; Waugh and Hall, 2002). However, other age of air tracers like $\mathrm{CO}_{2}$ do not confirm these high ages; the mesospheric loss of $\mathrm{SF}_{6}$ is generally considered to explain this discrepancy (Hall and Waugh, 1998; Reddmann et al., 2001). In order to confirm that the high mean age values derived from MIPAS observations during polar winters can be explained by the mesospheric sink of $\mathrm{SF}_{6}$, we performed model simulations with the Karlsruhe Simulation model of the Middle Atmosphere (KASIMA), a 3D-chemistry transport model which includes a module for $\mathrm{SF}_{6}$ chemistry in the mesosphere (Reddmann et al., 2001). $\mathrm{SF}_{6}$ is mainly destroyed via electron attachment and subsequent transformation to $\mathrm{HF}$.

\footnotetext{
${ }^{1}$ Funke, B., López-Puertas, M., Stiller, G., von Clarmann, T., Grabowski, U., and Linden, A.: Upper atmospheric $\mathrm{NO}_{\mathrm{x}}$ intrusions into the Arctic stratosphere during January to April 2004, to be submitted, Atmos. Chem. Phys. Discuss., 2008.
} 

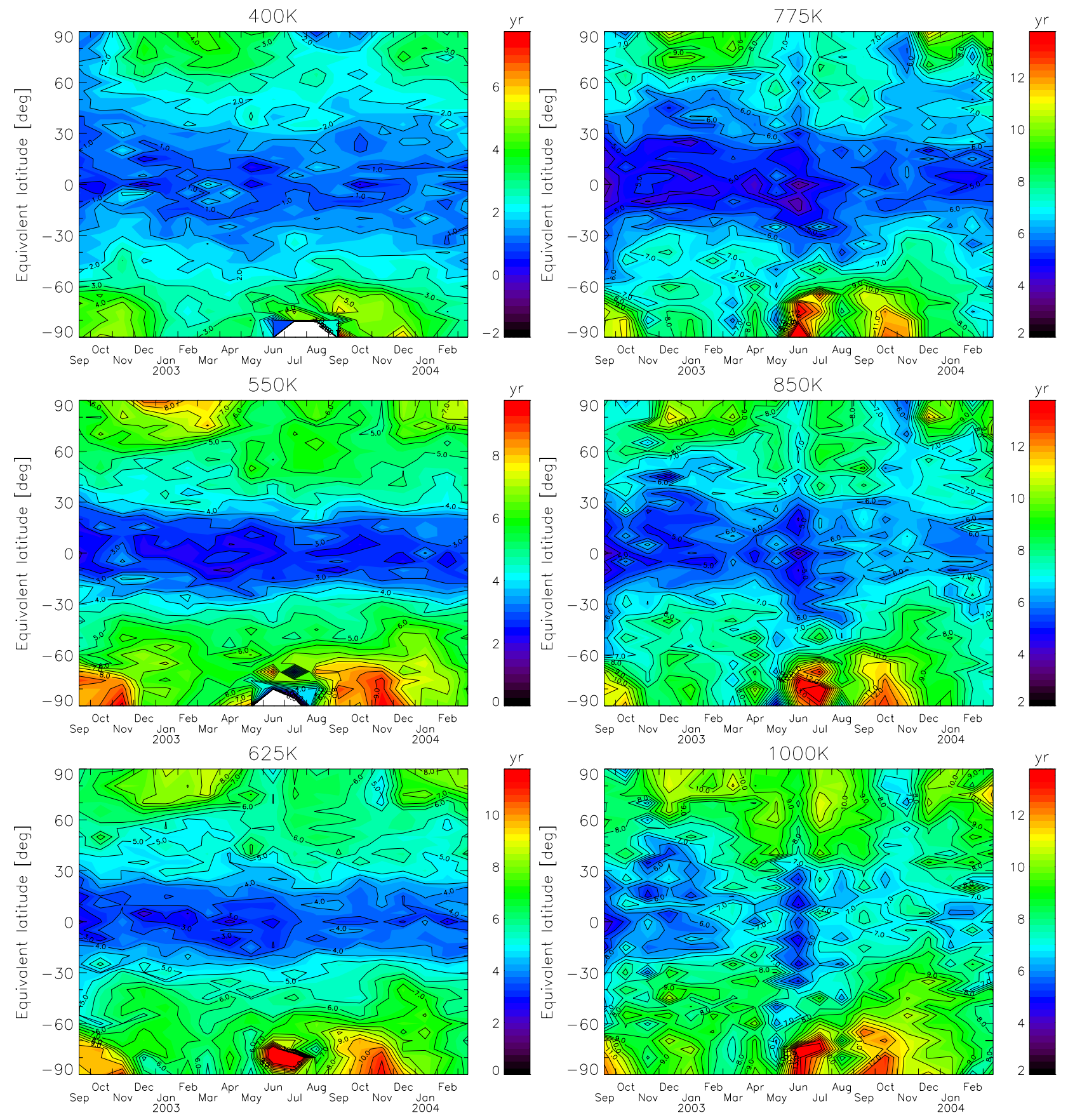

Fig. 9. Global time series of zonal distributions of the mean age of stratospheric air (versus equivalent latitude) at $400 \mathrm{~K}$ (left column, top), $550 \mathrm{~K}$ (left column, middle), $625 \mathrm{~K}$ (left column, bottom), $775 \mathrm{~K}$ (right column, top), $850 \mathrm{~K}$ (right column, middle), and $1000 \mathrm{~K}$ (right column, bottom), constructed from monthly means. Note the different colour scales in the panels. The white areas in the $400 \mathrm{~K}$ and $550 \mathrm{~K}$ panels are due to missing data due to clouds (PSCs).

For the present studies, the model version as described in Reddmann et al. (2001) is applied, but using ERA-40 analyses up to $18 \mathrm{~km}$, a relaxation term up to $1 \mathrm{hPa}$ and the prognostic part of the model above. From the lower pressure height boundary at $7 \mathrm{~km}$ up to $22 \mathrm{~km}$, the vertical resolution is $750 \mathrm{~m}$. From $22 \mathrm{~km}$ up to the upper boundary at $120 \mathrm{~km}$, the vertical spacing between the levels gradually increases to $3.8 \mathrm{~km}$. The triangular truncation, $\mathrm{T} 21$, used corresponds to a horizontal resolution of about $5.7^{\circ} \times 5.7^{\circ}$. A numerical time step of $12 \mathrm{~min}$ was used in the experiments. 

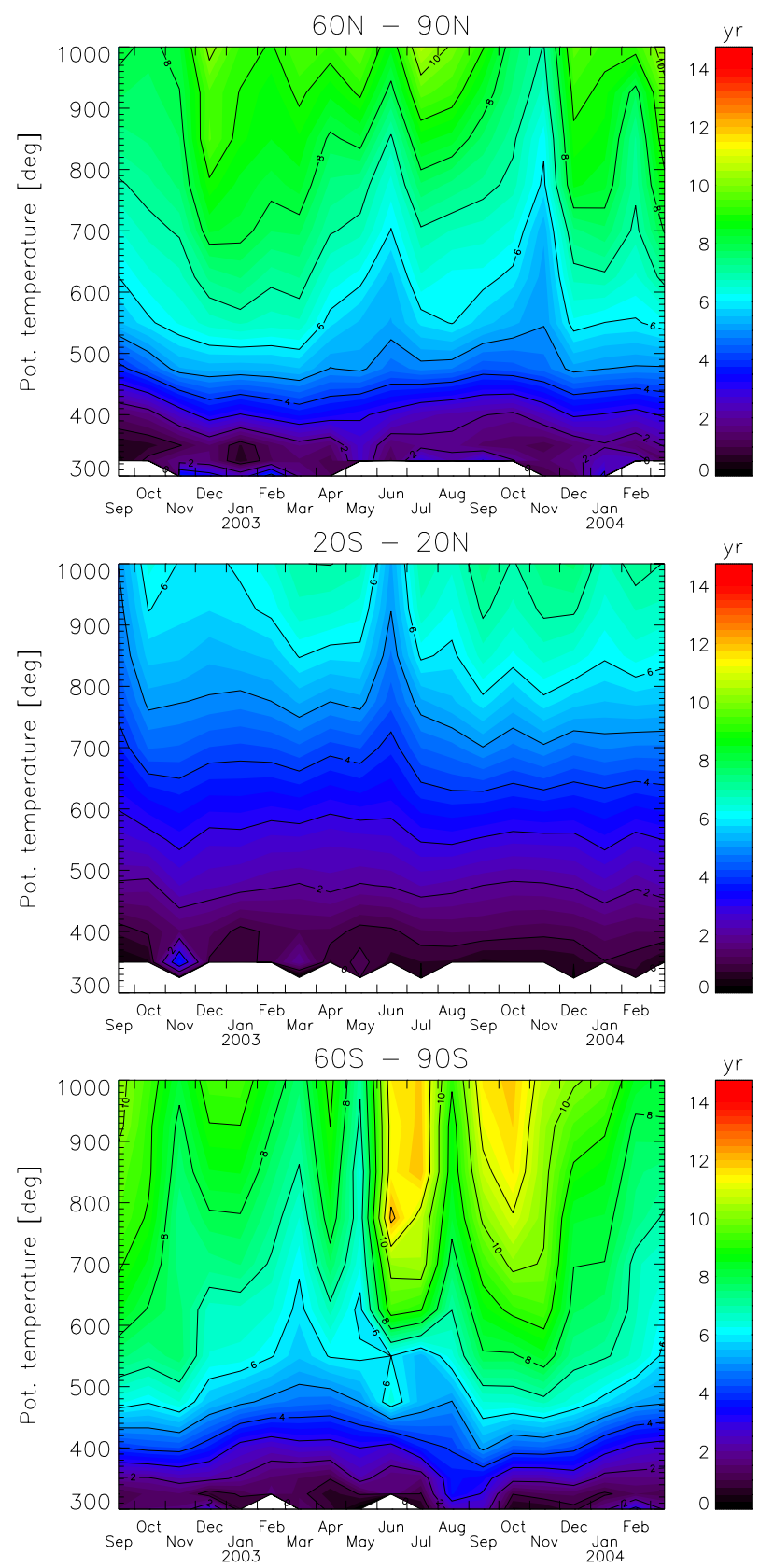

Fig. 10. Time series of mean age of stratospheric air vertical profiles (constructed from monthly zonal means) (potential temperature as vertical coordinates) for the equivalent latitude bands $60^{\circ} \mathrm{N}-$ $90^{\circ} \mathrm{N}$ (top), $20^{\circ} \mathrm{S}-20^{\circ} \mathrm{N}$ (middle), and $90^{\circ} \mathrm{S}-60^{\circ} \mathrm{S}$ (bottom).

As described in Reddmann et al. (2001) assumptions on the free thermal electron density and the reaction constants used influence the results. Here we use a ionisation model and include all back reactions, corresponding to an atmospheric lifetime of about 4500 years.
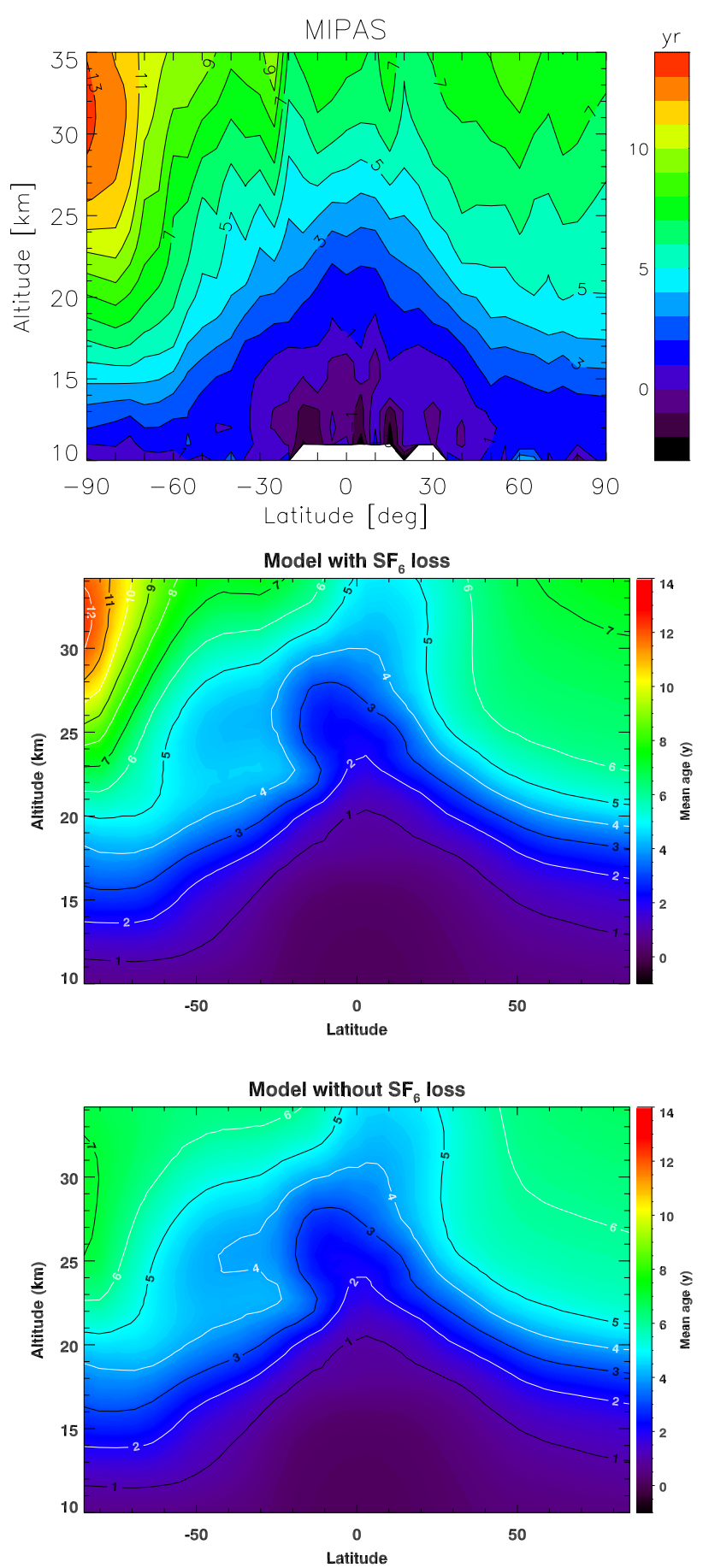

Fig. 11. Zonal mean distribution of mean age of stratospheric air for October 2003 from MIPAS (top), and KASIMA with (middle) and without (bottom) consideration of the $\mathrm{SF}_{6}$ loss reaction in the mesosphere, giving the apparent and the true mean age, respectively.

Figure 11 compares the monthly global mean distribution of MIPAS age of air for October 2003 (top panel) with KASIMA calculations including (middle panel) or disregard- 
ing (bottom panel) the mesospheric sink reaction. For the simulation with mesospheric loss, the apparent ages produced over the South pole are much closer to the MIPAS observations. In fact, the age of air calculated from this model run is 12 years or more, in very good agreement with the MIPAS observations. In contrast, treating $\mathrm{SF}_{6}$ as a fully stable tracer produces ages around 6 to 8 years over the South pole which has to be considered as the real transport time. This comparison confirms the assumption that high apparent ages as derived from $\mathrm{SF}_{6}$ are due to transport of $\mathrm{SF}_{6}$-depleted mesospheric air into the stratosphere.

The MIPAS time series show that such mesospheric intrusions are quite a frequent phenomenon. Further, the comparison roughly confirms the atmospheric lifetime of $\mathrm{SF}_{6}$ assessed by this study to be about 4500 years. Finally, the importance of the mesospheric $\mathrm{SF}_{6}$ sink is emphasized when comparing chemistry-transport models with age of air data derived from $\mathrm{SF}_{6}$. A more detailed analysis of the MIPAS data set together with model simulations of the global mean age of air distribution is planned for the near future.

\section{Conclusions}

We have derived mean age of air global distributions for the altitude range 6 to $35 \mathrm{~km}$ and the period September 2002 to March 2004 from MIPAS/Envisat SF $_{6}$ observations with a precision (in terms of the standard error of monthly $5^{\circ}$ zonal means based on approximately 100 single observations each) of $0.25 \mathrm{yr}$. The systematic error of the mean age of air data set is ruled by the uncertainty in spectroscopic data and a simplified non-LTE treatment in the $\mathrm{SF}_{6}$ retrieval approach which both might explain a potential bias of up to 1 year for altitudes below $35 \mathrm{~km}$ (up to 2 years above $35 \mathrm{~km}$ ), at certain latitudes and seasons. Comparison to previous observations reveals that the $\mathrm{SF}_{6}$ and mean age of air distributions from MIPAS are in very good agreement with those which indicates that the actual systematic error is considerably lower than its estimate. The available age of air data set gives the unprecedented opportunity to validate the transport schemes in chemistry-transport and chemistry-climate models.

The global data set from MIPAS for the period September 2002 to March 2004 reveals high seasonal variations and pronounced inter-hemispheric and inter-annual differences. In particular, in both polar vortices, frequent and, for the Southern Hemisphere, long-lasting intrusions of mesospheric air into the stratospheric vortex are observed, identified by very high apparent mean ages of 8 to 12 years and higher. The frequent mesospheric intrusions seen in MIPAS data may have been underestimated in the past and their role on chemistryclimate coupling needs further assessment. The mesospheric depletion of $\mathrm{SF}_{6}$ has been confirmed as source of the overestimation of the mean age of air by comparison of the observations with model calculations including and disregarding, respectively, the mesospheric chemical sink reactions of $\mathrm{SF}_{6}$.
Since MIPAS data contain independent information to quantify subsidence of mesospheric air (via $\mathrm{CO}$ or $\mathrm{CH}_{4}$, cf. Funke et al., 2005), the mesospheric sink strength, which is coupled to the mesospheric electron density, can be unambiguously quantified. This will help to improve the age of air assessment from $\mathrm{SF}_{6}$ and to make it more consistent with age of air estimates based on other tracers.

$\mathrm{SF}_{6}$ distributions discussed in this paper were retrieved from MIPAS high resolution spectra recorded in the original measurement mode between September 2002 and March 2004 before an instrument failure forced spectral degradation. The high seasonal variation and inter-annual differences observed are an obstacle to the unambiguous detection of a change in middle atmospheric global circulation from the currently available data set. However, 5 years of MIPAS level 1-B data are now available, and an extension of the mission for another 3 to 7 years is planned. This will provide a tremendous amount of information, assuming an equally accurate $\mathrm{SF}_{6}$ retrieval will be possible from the reduced spectral resolution data, which still has to be proven.

\section{Appendix A}

\section{Correction of $\mathrm{SF}_{6} \mathrm{vmr}$ biases caused by inadequate gain calibration}

The original MIPAS time series of $\mathrm{SF}_{6}$ is characterized by occasional unphysical values, which form secondary modes in the histogram of $\mathrm{SF}_{6}$ daily mean values. In order to reject or correct unrealistic values from the assessment of the age of the air without running risk of rejecting/correcting any true but unexpected data caused by unknown chemistry or physics, a search was made for an external data filter which is independent of the $\mathrm{SF}_{6}$ values themselves. Since discontinuities in $\mathrm{SF}_{6}$ mixing ratios were found to coincide exactly with the changes of the MIPAS gain calibration function, it was necessary to further assess the MIPAS calibration characteristics in the $\mathrm{SF}_{6}$ microwindow. MIPAS radiance calibration is done by application of one gain calibration function over a period of typically several days. For all limb sequences within such a gain calibration period, the spectra of the uppermost tangent altitude (approximately $68 \mathrm{~km}$ ) were averaged over time. This was done separately for spectra recorded during forward and backward movement of the interferometer mirrors, because calibration is done separately for forward and backward measurements.

Since, except for the two $\mathrm{CO}_{2} \mathrm{FB}$ laser band lines, all other atmospheric signals (e.g. $\mathrm{CO}_{2}$ laser hot band lines, $\mathrm{CO}_{2}$ isotope transitions, $\mathrm{H}_{2} \mathrm{O}, \mathrm{SF}_{6}$ ) are too weak to be noticeable, zero signal is expected in the gaps between the two prominent $\mathrm{CO}_{2}$ lines in the averaged spectra. Instead, for several gain calibration periods, systematic deviations from the zero radiance level were observed in version 4.61 spectral data (see Fig. 12). The amplitude of this error in the calibrated 

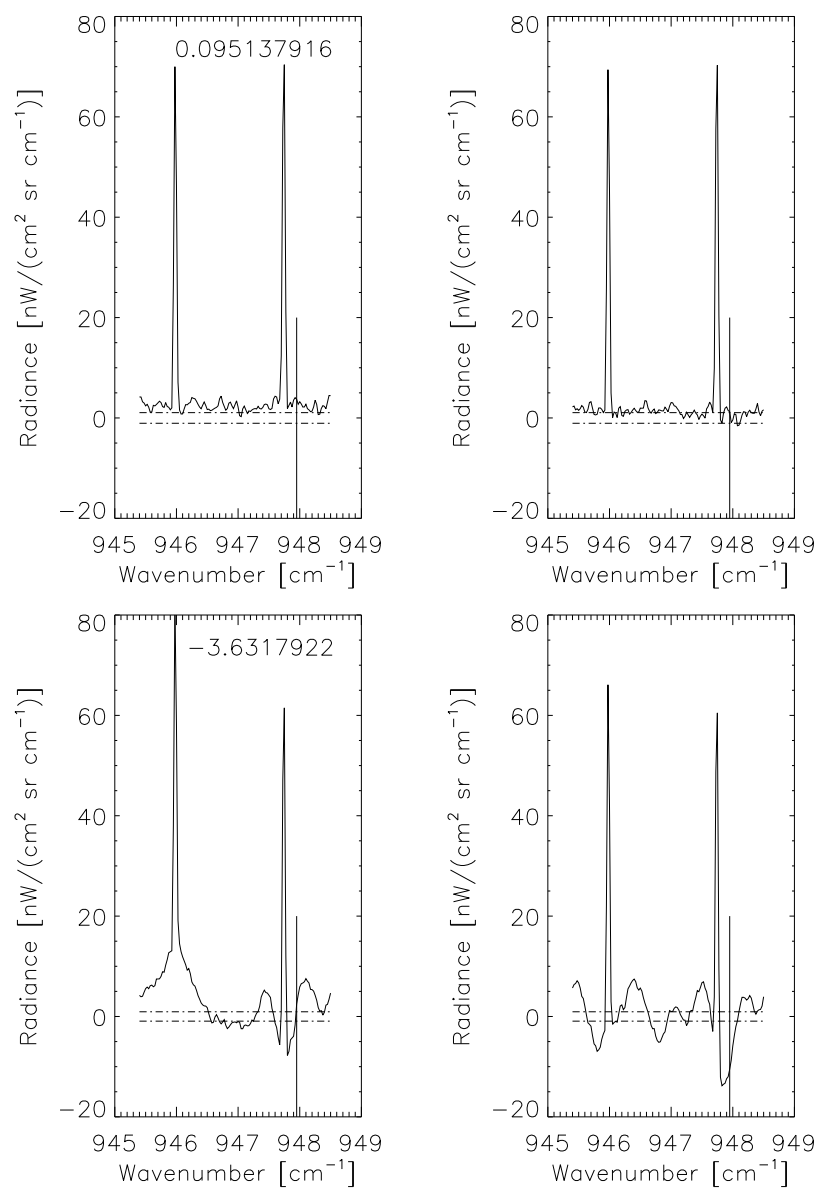

Fig. 12. Averaged radiance spectra of the highest tangent altitudes (i.e. approximately $68 \mathrm{~km}$ ) in the region of the $\mathrm{SF}_{6}$ signature for an example of close-to-perfect (top) and heavily distorted radiance calibration (bottom), respectively. The spectra were averaged over the period when one specific gain calibration function was applied; this is 8 to 9 December 2002 for the top panel and 28 to 30 April 2003 for the bottom panel. Averaging was done for forward (left) and backward (right) sweeps separately. The horizontal dashed lines indicate the expected NESR for the averaged spectra. The vertical solid line gives the position of the $\mathrm{SF}_{6}$ peak. The number provides the value of the gain index derived (for further details see text).

spectra is below the NESR of a single spectrum, and within the MIPAS radiance calibration specifications, but clearly visible in the averaged spectra.

Since the gain calibration functions are applied multiplicatively, it is not quite obvious how zero radiances can be affected and one might tend to attribute this artifact to the (additive) offset calibration function. The latter, however, is updated several times per orbit and does not coincide with the changes of the observed artifact. Thus, the nature of the detected artifact is still unexplained; since the details of the implementation of the calibration algorithm are beyond our direct control, we restrict ourselves to correcting the affected $\mathrm{SF}_{6}$ vmr data.

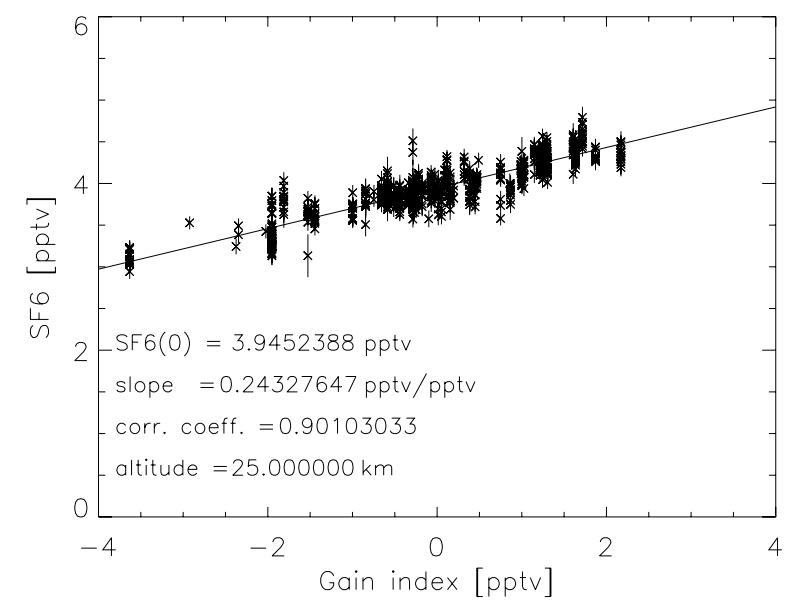

Fig. 13. Correlation between orbit-averaged $\mathrm{SF}_{6}$ vmrs and orbitrelated gain indices for the altitude level $25 \mathrm{~km}$. The vertical lines are the standard errors of the orbit means. The text provides the abscissa [pptv], slope, correlation coefficient, and altitude [km].

In a transparent atmosphere where radiative transfer is linear, and when measurement noise is equally distributed within the spectral gridpoints under consideration, the mapping of a systematic measurement error on the retrieved target mixing ratio is proportional to the product of the row vector containing the typical target spectral signal and the column vector containing the spectral error. Thus we estimate the retrieval error due to baseline oscillations caused by inadequate radiance calibration, in arbitrary units, as

$\Delta \mathrm{SF}_{6}=c \times \sum_{n=1}^{N} y_{\mathrm{SF}_{6} ; n} \times$

$\left(y_{\text {art.,fw } ; n}+y_{\text {art.,bw } ; n}-\frac{\sum_{n=1}^{N} y_{\text {art.,fw } ; n}}{N}-\frac{\sum_{n=1}^{N} y_{\text {art.,bw } n}}{N}\right)$

where $n$ runs over all $N$ spectral gridpoints of the $\mathrm{SF}_{6}$ microwindow except those where the prominent $\mathrm{CO}_{2}$ laser band lines are situated. $c$ is a constant of the dimension [pptv $\left.\left(\mathrm{W} /\left(\mathrm{cm}^{-2} \mathrm{srcm}^{-1}\right)\right)^{-2}\right] ; y_{\mathrm{SF}_{6} ; n}$ is the spectral signal of the $\mathrm{SF}_{6}$ band, and $y_{\text {art.,fw; } n}$ and $y_{\text {art.,bw; } n}$ are the systematic radiance errors at spectral gridpoint $n$ in the forward and backward spectra, respectively. The subtraction of the average background signal accounts for the average offset correction in our retrieval (von Clarmann et al., 2003b). This $\Delta \mathrm{SF}_{6}$ value, further referred to as gain index, was used as measure of the impact of erroneous gain calibration in further correction steps. In total, 87 gain calibration periods were analyzed by means of the spectral analysis described above, all of them applied within the period September 2002 to end of March 2004, and 87 gain indices were derived.

For correction of the $\mathrm{SF}_{6}$ vmrs derived from v4.61 spectral data and distorted by imperfect radiance calibration, $\mathrm{SF}_{6}$ global means $\left(90^{\circ} \mathrm{S}-90^{\circ} \mathrm{N}\right)$ per orbit for all altitude levels for two height grids, from $44 \mathrm{~km}$ to $7 \mathrm{~km}$ and $1500 \mathrm{~K}$ to 

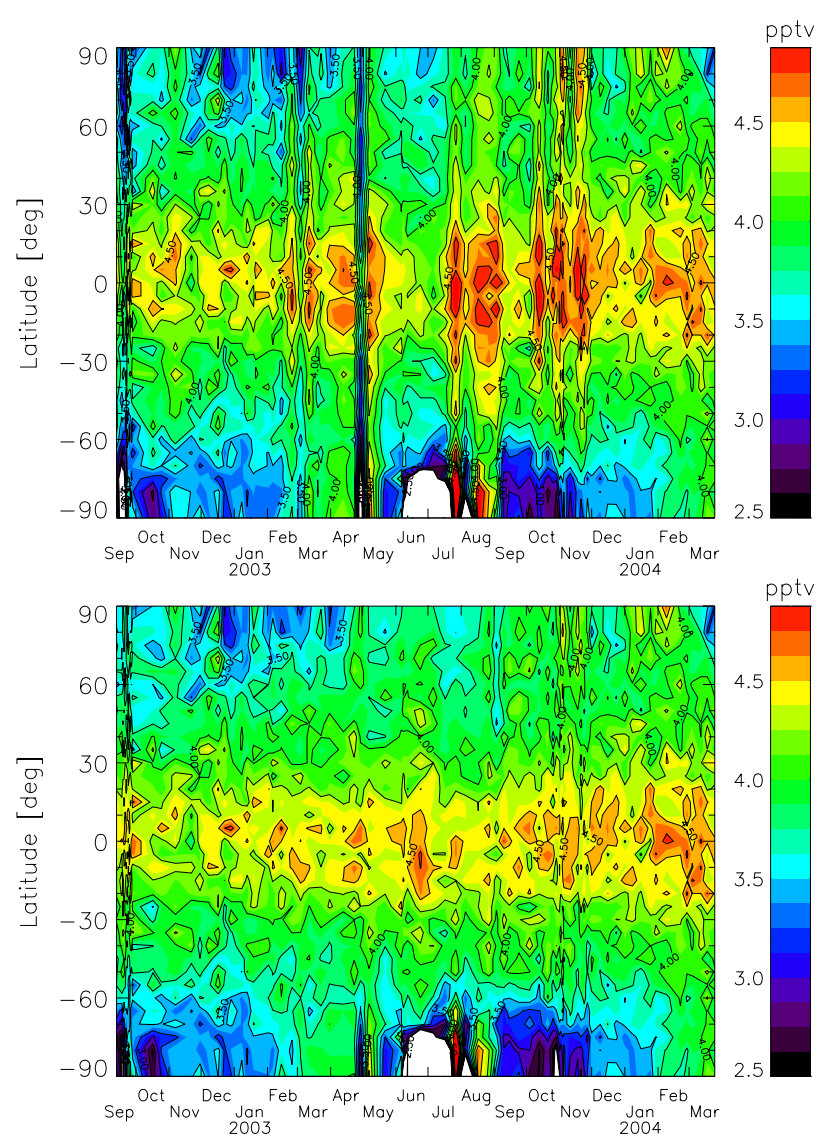

Fig. 14. Time series of $\mathrm{SF}_{6}$ zonal mean distributions at $25 \mathrm{~km}$ altitude before (top) and after (bottom) correction for the bias due to inadequate radiance calibration. Remnants of the gain-calibration caused artifacts remained for some days and regions, particularly for high Southern latitudes on 29 April 2003, 7 May 2003, and 27 July 2003, and for high Northern latitudes for some days during November 2003. White areas indicate $\mathrm{SF}_{6}$ values below $2.5 \mathrm{pptv}$ or missing data due to clouds (PSCs).

$350 \mathrm{~K}$, were calculated. These orbit mean values for each altitude were correlated with the gain indices derived for the respective orbits. A linear relationship between orbit-mean $\mathrm{SF}_{6}$ vmrs and gain indices was established for all altitudes and potential temperature levels (see Fig. 13). From the linear regression of this correlation an additive correction term for each altitude or potential temperature level was derived. For all daily and monthly mean distributions, each $\mathrm{SF}_{6}$ value derived from $\mathrm{v} 4.61$ spectral data has been corrected by the following expression

$$
\begin{aligned}
\mathrm{SF}_{6}{ }^{\text {korr }}(z, \text { orbit })= & \mathrm{SF}_{6}{ }^{\text {original }}(z, \text { orbit })- \\
& a(z) \times \text { gain_index }(\text { orbit })
\end{aligned}
$$

with $a(z)$ being the altitude dependent slope of the linear regression $\left(\mathrm{SF}_{6}\right.$ vs. gain index) (see Fig. 13) and gain_index(orbit) the orbit-dependent gain index characterizing the error due to inadequate gain calibration. $a(z)$ is of the order of 1.0 for $44 \mathrm{~km}$ altitude and decreases smoothly to values around 0.06 for $10 \mathrm{~km}$, while the gain index varies between -4.0 and +2.5 for the gain calibration periods under investigation. For $\mathrm{SF}_{6}$ means built from more than one gain calibration periods, the weighted mean of the gain indices was applied.

It should be noted that the method described above could lead to an unwanted artificial component in the temporal variation of $\mathrm{SF}_{6}$ in terms of seasonal variation or trend, if the gain index varied systematically with time as well. The latter, however, has been falsified, i.e. it was found that the gain index varied randomly with time rather than systematically.

Within this work, scientific analysis of $\mathrm{SF}_{6}$ distributions, and, in particular, the derivation of the tropospheric trend and mean age of stratospheric air, is based on the corrected $\mathrm{SF}_{6}$ data derived from $\mathrm{v} 4.61$ spectral data; the $\mathrm{SF}_{6} \mathrm{vmr}$ derived from v4.62 spectral data are used without correction. Figure 14 presents the time series of global $\mathrm{SF}_{6}$ at $25 \mathrm{~km}$ altitude before and after correction. In summary, while the correction is substantial, the expected $\mathrm{SF}_{6} \mathrm{vmr}$ values or any expected structures are never used in the correction scheme. Instead, the correction relies fully and solely on the detected gain calibration peculiarities.

Acknowledgements. Re-processed MIPAS level 1-B data were provided by ESA for scientific analysis. The research work of the IMK MIPAS/Envisat group has been funded by EC via the Integrated Project SCOUT-O3 (contract No. 505390-GOCE-CT2004), BMBF via project No. 50EE0512, and the German Research Foundation (DFG) within the Program of Emphasis CAWSES via project STI 210/4-1. We gratefully acknowledge the provision of $\mathrm{SF}_{6}$ surface flask and in situ measurements by the National Oceanic and Atmospheric Administration Earth System Research Laboratory, Global Monitoring Division, and helpful comments on the manuscript by B. Hall.

Edited by: M. Dameris

\section{References}

Andrews, A. E., Boering, K. A., Daube, B. C., Wofsy, S. C., Loewenstein, M., Jost, H., Podolske, J. R., Webster, C. R., Herman, R. L., Scott, D. C., Flesch, G. J., Moyer, E. J., Elkins, J. W., Dutton, G. S., Hurst, D. F., Moore, F. L., Ray, E. A., Romashkin, P. A., and Strahan, S. E.: Mean ages of stratospheric air derived from in situ observations of $\mathrm{CO}_{2}, \mathrm{CH}_{4}$, and $\mathrm{N}_{2} \mathrm{O}$, J. Geophys. Res., 106, 32 295-32 314, doi:10.1029/2001JD000465, 2001.

Austin, J. and Li, F.: On the relationship between the strength of the Brewer-Dobson circulation and the age of stratospheric air, Geophys. Res. Lett., 33, L17807, doi:10.1029/2006GL026867, 2006.

Boering, K. A., Wofsy, S. C., Daube, B. C., Schneider, H. R., Loewenstein, M., Podolske, J. R., and Conway, T. J.: Stratospheric Mean Ages and Transport Rates from Observations of Carbon Dioxide and Nitrous Oxide, Science, 274, 1340-1343, doi:10.1126/science.274.5291.1340, 1996. 
Burgess, A. B., Grainger, R. G., Dudhia, A., Payne, V. H., and Jay, V. L.: MIPAS measurement of sulphur hexafluoride $\left(\mathrm{SF}_{6}\right)$, Geophys. Res. Lett., 31, L05112, doi:10.1029/2003GL019143, 2004.

Burgess, A. B., Grainger, R. G., and Dudhia, A.: Zonal mean atmospheric distribution of sulphur hexafluoride $\left(\mathrm{SF}_{6}\right)$, Geophys. Res. Lett., 33, L07809, doi:10.1029/2005GL025410, 2006.

Butchart, N., Scaife, A. A., Bourqui, M., de Grandpre, J., Hare, S. H. E., Kettleborough, J., Langematz, U., Manzini, E., Sassi, F., Shibata, K., Shindell, D., and Sigmond, M.: Simulations of anthropogenic change in the strength of the BrewerDobson circulation, Clim. Dynam., 27, 727-741, doi:10.1007/ s00382-006-0162-4, 2006.

Elkins, J. W., Fahey, D. W., Gilligan, J. M., Dutton, G. S., Baring, T. J., Volk, C. M., Dunn, R. E., Myers, R. C., Montzka, S. A., Wamsley, P. R., Hayden, A. H., Butler, J. H., Thompson, T. M., Swanson, T. H., Dlugokencky, E. J., Novelli, P. C., Hurst, D. F., Lobert, J. M., Ciciora, S. J., McLaughlin, R. J., Thompson, T. L., Winkler, R. H., Fraser, P. J., Steele, L. P., and Lucarelli, M. P.: Airborne gas chromatograph for in situ measurements of long-lived species in the upper troposphere and lower stratosphere, Geophys. Res. Lett., 23, 347-350, doi: 10.1029/96GL00244, 1996.

Engel, A., Bönisch, H., Brunner, D., Fischer, H., Franke, H., Günther, G., Gurk, C., Hegglin, M., Hoor, P., Königstedt, R., Krebsbach, M., Maser, R., Parchatka, U., Peter, T., Schell, D., Schiller, C., Schmidt, U., Spelten, N., Szabo, T., Weers, U., Wernli, H., Wetter, T., and Wirth, V.: Highly resolved observations of trace gases in the lowermost stratosphere and upper troposphere from the Spurt project: an overview, Atmos. Chem. Phys., 6, 283-301, 2006a.

Engel, A., Möbius, T., Haase, H.-P., Bönisch, H., Wetter, T., Schmidt, U., Levin, I., Reddmann, T., Oelhaf, H., Wetzel, G., Grunow, K., Huret, N., and Pirre, M.: Observation of mesospheric air inside the arctic stratospheric polar vortex in early 2003, Atmos. Chem. Phys., 6, 267-282, 2006 b.

Fischer, H., Birk, M., Blom, C., Carli, B., Carlotti, M., von Clarmann, T., Delbouille, L., Dudhia, A., Ehhalt, D., Endemann, M., Flaud, J. M., Gessner, R., Kleinert, A., Koopmann, R., Langen, J., López-Puertas, M., Mosner, P., Nett, H., Oelhaf, H., Perron, G., Remedios, J., Ridolfi, M., Stiller, G., and Zander, R.: MIPAS: an instrument for atmospheric and climate research, Atmos. Chem. Phys. Discuss., 7, 8795-8893, 2007,

http://www.atmos-chem-phys-discuss.net/7/8795/2007/.

Flaud, J.-M., Piccolo, C., Carli, B., Perrin, A., Coudert, L. H., Teffo, J.-L., and Brown, L. R.: Molecular line parameters for the MIPAS (Michelson Interferometer for Passive Atmospheric Sounding) experiment, Atmos. Oceanic Opt., 16, 172-182, 2003.

Funke, B., López-Puertas, M., Stiller, G. P., von Clarmann, T., and Höpfner, M.: A new non-LTE Retrieval Method for Atmospheric Parameters From MIPAS-ENVISAT Emission Spectra, Adv. Space Res., 27, 1099-1104, 2001.

Funke, B., López-Puertas, M., Gil-López, S., von Clarmann, T., Stiller, G. P., Fischer, H., and Kellmann, S.: Downward transport of upper atmospheric $\mathrm{NO}_{\mathrm{x}}$ into the polar stratosphere and lower mesosphere during the Antarctic 2003 and Arctic 2002/2003 winters, J. Geophys. Res., 110, D24308, doi:10.1029/ 2005JD006463, 2005.

Funke, B., López-Puertas, M., , Bermejo-Pantaleón, D., von Clarmann, T., Stiller, G. P., Höpfner, M., Grabowski, U., and Kauf- mann, M.: Analysis of nonlocal thermodynamic equilibrium CO $4.7 \mu \mathrm{m}$ fundamental, isotopic and hot band emissions measured by the Michelson Interferometer for Passive Atmospheric Sounding on Envisat, J. Geophys. Res., 112, D11305, doi:10.1029/ 2006JD007933, 2007.

Geller, L. S., Elkins, J. W., Lobert, J. M., Clarke, A. D., Hurst, D. F., Butler, J. H., and Myers, R. C.: Tropospheric SF 6 : Observed latitudinal distribution and trends, derived emissions and interhemispheric exchange time, Geophys. Res. Lett., 24, 675678, doi:10.1029/97GL00523, 1997.

Glatthor, N., von Clarmann, T., Fischer, H., Funke, B., Gil-López, S., Grabowski, U., Höpfner, M., Kellmann, S., Linden, A., López-Puertas, M., Mengistu Tsidu, G., Milz, M., Steck, T., Stiller, G. P., and Wang, D.-Y.: Retrieval of stratospheric ozone profiles from MIPAS/ENVISAT limb emission spectra: a sensitivity study, Atmos. Chem. Phys., 6, 2767-2781, 2006, http://www.atmos-chem-phys.net/6/2767/2006/.

Gloor, M., Dlugokencky, E., Brenninkmeijer, C., Horowitz, L., Hurst, D.F., Dutton, G., Crevoisier, C., Machida, T., and Tans, P.: Three-dimensional $\mathrm{SF}_{6}$ data and tropospheric transport simulations: Signals, modeling accuracy, and implications for inverse modeling, J. Geophys. Res., 112, D15112, doi:10.1029/ 2006JD007973, 2007.

Hall, T. M. and Waugh, D. W.: Influence of nonlocal chemistry on tracer distributions: Inferring the mean age of air from $\mathrm{SF}_{6}$, J. Geophys. Res., 103, 13,327-13,336, doi:10.1029/98JD00170, 1998.

Hauchecorne, A., Bertaux, J.-L., Dalaudier, F., Russell III, J. M., Mlynczak, M. G., Kyrölä, E., and Fussen, D.: Large increase of $\mathrm{NO}_{2}$ in the north polar mesosphere in January-February 2004: Evidence of a dynamical origin from GOMOS/ENVISAT and SABER/TIMED data, Geophys. Res. Lett., 34, L03810, doi:10. 1029/2006GL027628, 2007.

Höpfner, M., Oelhaf, H., Wetzel, G., Friedl-Vallon, F., Kleinert, A., Lengel, A., Maucher, G., Nordmeyer, H., Glatthor, N., Stiller, G. P., von Clarmann, T., Fischer, H., Kröger, C., and Deshler, T.: Evidence of scattering of tropospheric radiation by PSCs in mid-IR limb emission spectra: MIPAS-B observations and KOPRA simulations, Geophys. Res. Lett., 29, 1278, doi: 10.1029/2001GL014443, 2002.

Kida, H.: General circulation of air parcels and transport characteristics derived from a hemispheric GCM, Part 2, Very long-term motions of air parcels in the troposphere and stratosphere, J. Meteorol. Soc. Jpn., 61, 510-522, 1983.

Kiefer, M., von Clarmann, T., and Grabowski, U.: State parameter Data Base for MIPAS Data Analysis, Adv. Space Res., 30, 23872392, 2002.

Ko, M. K. W., Sze, N. D., Wang, W.-C., Shia, G., Goldman, A., Murcray, F. J., Murcray, D. G., and Rinsland, C. P.: Atmospheric sulfur hexafluoride: Sources, sinks and greenhouse warming, J. Geophys. Res., 98, 10,499-10,507, doi:10.1029/93JD00228, 1993.

Konopka, P., Engel, A., Funke, B., Müller, R., Grooß, J.-U., Günther, G., Wetter, T., Stiller, G. P., von Clarmann, T., Glatthor, N., Oelhaf, H., Wetzel, G., López-Puertas, M., Pirre, M., Huret, N., and Riese, M.: Ozone loss driven by nitrogen oxides and triggered by stratospheric warmings can outweigh the effect of halogens, J. Geophys. Res., 112, D05105, doi:10.1029/ 2006JD007064, 2007. 
López-Puertas, M. and Taylor, F. W.: Non-LTE radiative transfer in the Atmosphere, World Scientific Pub., Singapore, 2001.

Maiss, M. and Levin, I.: Global increase of $\mathrm{SF}_{6}$ observed in the atmosphere, Geophys. Res. Lett., 21, 569-572, 1994.

Manney, G. L., Krüger, K., Sabutis, J. L., Sena, S. A., and Pawson, S.: The remarkable 2003-2004 winter and other recent warm winters in the Arctic stratosphere since the late 1990s, J. Geophys. Res., 110, D04107, doi:10.1029/2004JD005367, 2005a.

Manney, G. L., Sabutis, J. L., Allen, D. R., Lahoz, W. A., Scaife, A. A., Randall, C. E., Pawson, S., Naujokat, B., and Swinbank, R.: Simulations of Dynamics and Transport During the September 2002 Antarctic Major Warming, J. Atmos. Sci., 62, 690-707, 2005b.

Morris, R. A., Miller, T. M., Viggiano, A., and Paulson, J. F.: Effects of electron and ion reactions on atmospheric lifetimes of fully fluorinated compounds, J. Geophys. Res., 100, 1287-1294, doi:10.1029/94JD02399, 1995.

Nemtchinov, V. and Varanasi, P.: Thermal infrared absorption cross-sections of $\mathrm{CF}_{4}$ for atmospheric applications, J. Quant. Spectrosc. Radiat. Transfer, 82, 461-471, doi:10.1016/ S0022-4073(03)00170-5, 2003.

Nett, H., Carli, B., Carlotti, M., Dudhia, A., Fischer, H., Flaud, J.M., Perron, G., Raspollini, P., and Ridolfi, M.: MIPAS Ground Processor and Data Products, in: Proc. IEEE 1999 International Geoscience and Remote Sensing Symposium, 28 June-2 July 1999, Hamburg, Germany, 1692-1696, 1999.

Norton, H. and Beer, R.: New apodizing functions for Fourier spectrometry, J. Opt. Soc. Am, 66, 259-264, (Errata J. Opt. Soc. Am., 67, 419,1977), 1976.

Randall, C. E., Harvey, V. L., Singleton, C. S., Bernath, P. F., Boone, C. D., and Kozyra, J. U.: Enhanced $\mathrm{NO}_{\mathrm{x}}$ in 2006 linked to strong upper stratospheric Arctic vortex, Geophys. Res. Lett., 22, L18811, doi:10.1029/2006GL027160, 2006.

Randall, C. E., Harvey, V. L., Singleton, C. S., Bailey, S. M., Bernath, P. F., Codrescu, M., Nakajima, H., and Russell III, J. M.: Energetic particle precipitation effects on the Southern Hemisphere stratosphere in 1992-2005, J. Geophys. Res., 112, D08308, doi:10.1029/2006JD007696, 2007.

Ravishankara, A. R., Solomon, S., Turnipseed, A. A., and Warren, R. F.: Atmospheric lifetimes of long-lived halogenated species, Science, 259, 194-199, doi:10.1126/science.259.5092. 194, 1993.

Ray, E. A., Moore, F. L., Elkins, J. W., Dutton, G. S., Fahey, D. W., Vömel, H., Oltmans, S. J., and Rosenlof, K. H.: Transport into the Northern Hemisphere lowermost stratosphere revealed by in situ tracer measurements, J. Geophys. Res., 104, 26 565-26 580, doi:10.1029/1999JD900323, 1999.

Ray, E. A., Moore, F. L., Elkins, J. W., Hurst, D. F., Romashkin, P. A., S.Dutton, G., and Fahey, D. W.: Descent and mixing in the 1999-2000 northern polar vortex inferred from in situ tracer measurements, J. Geophys. Res., 107, 8285, doi:10.1029/ 2001JD000961, 2002.

Reddmann, T., Ruhnke, R., and Kouker, W.: Three-dimensional model simulations of $\mathrm{SF}_{6}$ with mesospheric chemistry, J. Geophys. Res., 106, 14 525-14 537, doi:10.1029/2000JD900700, 2001.

Rinsland, C. P., Brown, L. R., and Farmer, C. B.: Infrared spectroscopic detection of sulfur hexafluoride $\left(\mathrm{SF}_{6}\right)$ in the lower stratosphere and upper troposphere, J. Geophys. Res., 95, 5577-5585,
doi:10.1029/89JD03413, 1990.

Rinsland, C. P., Gunson, M. R., Abrams, M. C., Lowes, L. L., Zander, R., and Mahieu, E.: ATMOS/ATLAS1 measurements of sulfur hexafluoride $\left(\mathrm{SF}_{6}\right)$ in the lower stratosphere and upper troposphere, J. Geophys. Res., 98, 20 491-20 494, doi:10.1029/ 93JD02258, 1993.

Rinsland, C. P., Goldman, A., Stephen, T. M., Chiou, L. S., Mahieu, E., and Zander, R.: $\mathrm{SF}_{6}$ ground-based infrared solar absorption measurements: long-term trend, pollution events, and a search for $\mathrm{SF}_{5} \mathrm{CF}_{3}$ absorption, J. Quant. Spectrosc. Radiat. Transfer, 78, 41-53, 2003.

Rinsland, C. P., Boone, C., Nassar, R., Walker, K., Bernath, P., Mahieu, E., Zander, R., McConnell, J. C., and Chiou, L.: Trends of $\mathrm{HF}, \mathrm{HCl}, \mathrm{CCl}_{2} \mathrm{~F}_{2}, \mathrm{CCl}_{3} \mathrm{~F}, \mathrm{CHCLF}_{2}$ (HCFC-22), and $\mathrm{SF}_{6}$ in the lower stratosphere from Atmospheric Chemistry Experiment (ACE) and Atmospheric Trace Molecule Spectroscopy (ATMOS) measurements near $30^{\circ} \mathrm{N}$ latitude, Geophys. Res. Lett., 32, L16S03, doi:10.1029/2005GL022415, 2005.

Rodgers, C. D.: Inverse Methods for Atmospheric Sounding: Theory and Practice, Vol. 2, Series on Atmospheric, Oceanic and Planetary Physics, edited by: F. W. Taylor, World Scientific, 2000.

Rothman, L. S., Jacquemart, D., Barbe, A., Benner, D. C., Birk, M., Brown, L. R., Carleer, M. R., Chackerian Jr., C., Chance, K., Coudert, L. H., Dana, V., Devi, V. M., Flaud, J.-M., Gamache, R. R., Goldman, A., Hartmann, J.-M., Jucks, K. W., Maki, A. G., Mandin, J.-Y., Massie, S. T., Orphal, J., Perrin, A., Rinsland, C. P., Smith, M. A. H., Tennyson, J., Tolchenov, R. N., Toth, R. A., Vander Auwera, J., Varanasi, P., and Wagner, G.: The HITRAN 2004 molecular spectroscopic database, J. Quant. Spectrosc. Radiat. Transfer, 96, 139-204, doi:10.1016/j.jqsrt.2004.10. 008, 2005.

Seppälä, A., Verronen, P. T., Clilverd, M. A., Randall, C. E., Tamminen, J., Sofieva, V., Backman, L., and Kyrölä, E.: Arctic and Antarctic polar winter $\mathrm{NO}_{\mathrm{x}}$ and energetic particle precipitation in 2002-2006, Geophys. Res. Lett., 34, L12810, doi: 10.1029/2007GL029733, 2007.

Spang, R., Remedios, J. J., and Barkley, M. P.: Colour indices for the detection and differentiation of cloud types in infra-red limb emission spectra, Adv. Space Res., 3, 1041-1047, doi:10.1016/ S0273-1177(03)00585-4, 2004.

Steck, T.: Methods for determining regularization for atmospheric retrieval problems, Appl. Opt., 41, 1788-1797, 2002.

Steck, T. and von Clarmann, T.: Constrained profile retrieval applied to the observation mode of the Michelson Interferometer for Passive Atmospheric Sounding, Appl. Opt., 40, 3559-3571, 2001.

Stiller, G. P., von Clarmann, T., Funke, B., Glatthor, N., Hase, F., Höpfner, M., and Linden, A.: Sensitivity of trace gas abundances retrievals from infrared limb emission spectra to simplifying approximations in radiative transfer modelling, J. Quant. Spectrosc. Radiat. Transfer, 72, 249-280, 2002.

Strunk, M., Engel, A., Schmidt, U., Volk, C. M., Wetter, T., Levin, I., and Glatzel-Mattheier, H.: $\mathrm{CO}_{2}$ and $\mathrm{SF}_{6}$ as stratospheric age tracers: consistency and the effect of mesospheric $\mathrm{SF}_{6}$-loss, Geophys. Res. Lett., 27, 341-344, doi:10.1029/1999GL011044, 2000.

Tikhonov, A.: On the solution of incorrectly stated problems and method of regularization, Dokl. Akad. Nauk. SSSR, 151, 501- 
504, 1963.

Varanasi, P., Li, Z., Nemtchinov, V., and Cherukuri, A.: Spectral Absorption-Coefficient Data on HCFC-22 and $\mathrm{SF}_{6}$ for RemoteSensing Applications, J. Quant. Spectrosc. Radiat. Transfer, 52, 323-332, 1994.

Volk, C. M., Elkins, J. W., Fahey, D. W., Dutton, G. S., Gilligan, J. M., Loewenstein, M., Podolske, J. R., Chan, K. R., and Gunson, M. R.: Evaluation of source gas lifetimes from stratospheric observations, J. Geophys. Res., 102, 25 543-25 564, doi: 10.1029/97JD02215, 1997.

von Clarmann, T., Ceccherini, S., Doicu, A., Dudhia, A., Funke, B., Grabowski, U., Hilgers, S., Jay, V., Linden, A., LópezPuertas, M., Martín-Torres, F.-J., Payne, V., Reburn, J., Ridolfi, M., Schreier, F., Schwarz, G., Siddans, R., and Steck, T.: A blind test retrieval experiment for infrared limb emission spectrometry, J. Geophys. Res., 108, 4746, doi:10.1029/2003JD003835, 2003a.

von Clarmann, T., Glatthor, N., Grabowski, U., Höpfner, M., Kellmann, S., Kiefer, M., Linden, A., Mengistu Tsidu, G., Milz, M., Steck, T., Stiller, G. P., Wang, D. Y., Fischer, H., Funke, B., Gil-López, S., and López-Puertas, M.: Retrieval of temperature and tangent altitude pointing from limb emission spectra recorded from space by the Michelson Interferometer for Passive Atmospheric Sounding (MIPAS), J. Geophys. Res., 108, 4736, doi:10.1029/2003JD003602, 2003b.
Waugh, D. W. and Hall, T. M.: Age of stratospheric air: theory, observations, and models, Rev. Geophys., 40, 1010, doi:10.1029/ 2000RG000101, 2002.

Waugh, D. W., Strahan, S. E., and Newman, P. A.: Sensitivity of stratospheric inorganic chlorine to differences in transport, Atmos. Chem. Phys., 7, 4935-4941, 2007, http://www.atmos-chem-phys.net/7/4935/2007/.

Zander, R., Rinsland, C. P., and Demoulin, P.: Infrared spectroscopic measurements of the vertical column abundance of sulfur hexafluoride, $\mathrm{SF}_{6}$, from the ground, J. Geophys. Res., 96, 15 447-15 454, doi:10.1029/91JD01214, 1991.

Zander, R., Gunson, M. R., Farmer, C. B., Rinsland, C. P., Irion, F. W., and Mahieu, E.: The 1985 chlorine and fluorine inventories in the stratosphere based on ATMOS observations at $30^{\circ}$ North latitude, J. Atmos. Chem., 15, 171-186, doi:10.1007/ BF00053758, 1992. 